\title{
Testing of Explosives Mixed with Clay to Determine Maximum Explosive Content of Non-Reactive Mixtures
}

\author{
LeRoy Green \\ Raul Garza \\ Jon Maienschein \\ Cesar Pruneda
}

July 21, 1998

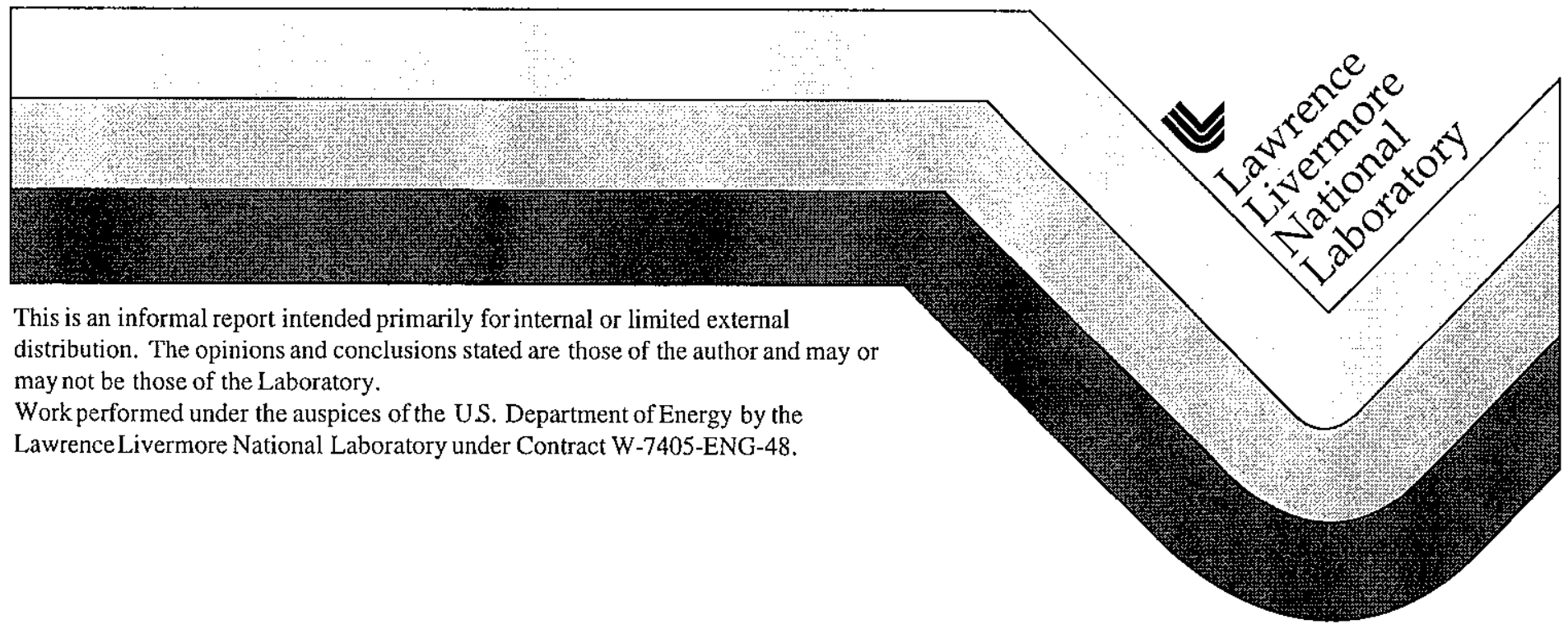




\section{DISCLAIMER}

This document was prepared as an account of work sponsored by an agency of the United States Government. Neither the United States Government nor the University of California nor any of their employees, makes any warranty, express or implied, or assumes any legal liability or responsibility for the accuracy, completeness, or usefulness of any information, apparatus, product, or process disclosed, or represents that its use would not infringe privately owned rights. Reference herein to any specific commercial product, process, or service by trade name, trademark, manufacturer, or otherwise, does not necessarily constitute or imply its endorsement, recommendation, or favoring by the United States Government or the University of California. The views and opinions of authors expressed herein do not necessarily state or reflect those of the United States Government or the University of California, and shall not be used for advertising or product endorsement purposes.

This report has been reproduced directly from the best available copy.

Available to DOE and DOE contractors from the Office of Scientific and Technical Information

P.O. Box 62, Oak Ridge, TN 37831

Prices available from (615) 576-8401, FTS 626-8401

Available to the public from the

National Technical Information Service

U.S. Department of Commerce

5285 Port Royal Rd.,

Springfield, VA 22161 


\title{
Testing of Explosives Mixed with Clay to Determine Maximum Explosive Content of Non-Reactive Mixtures
}

\author{
LeRoy Green, Raul Garza, Jon Maienschein, César Pruneda
}

July 21, 1998

\begin{abstract}
This report contains a detailed description of the experiments conducted to demonstrate that debris from explosives testing in a shot tank that contains 4 weight percent or less of explosive is non-reactive under the specified testing protocol in the Code of Federal Regulations. As such it is a companion report to UCRL-ID-128999, "Program for Certification of Waste from Contained Firing Facility - Establishment of Waste as Non-Reactive and Discussion of Potential Waste Generation Problems."
\end{abstract}

\subsection{Introduction}

The determination of the reactive nature of explosive-contaminated materials is of interest in considering disposal of contaminated shot debris, and in treatment or disposal of dirt contaminated with explosives.

We carried out a series of test with mixtures of explosives and clay floor sweeping compound to address the issue of contaminated shot debris from an enclosed firing tank; these tests were designed to determine the maximum level of explosives that is non-reactive as specified by the United Nations tests. ${ }^{1}$ The tests are summarized and the conclusions related to waste disposal are reported by. Green. ${ }^{2}$

We tested several explosives mixed with clay in small-scale handling and thermal tests. We tested the most sensitive of those, PETN, mixed with clay in larger-scale fire and detonation tests. Because the results are also of interest for other applications, here we report the details of the tests and resulting data. We also report on the use of Differential Scanning Calorimetry to measure the concentration of explosive in a very dilute sample.

\subsection{Testing Protocol}

The protocol for determining whether a material is a Class 1 explosive is defined by the United Nations. ${ }^{1}$ as specified in 49 CFR 173.57. The protocol, as detailed in a series of flowcharts (Figures 10.1, 10.2, and 10.3 in Reference 1), requires a set of tests identified as Series 3 and Series 6 . These tests address the reactivity of the material by itself, and as packaged for shipment. If a material shows no hazardous nature in these tests (as 
defined below), then it is qualified as not Class 1 , and hence for our purposes not reactive.

In addition to the tests specified by the United Nations, we explored the use of thermal analysis by Differential Scanning Calorimetry (DSC) to determine the concentration of explosives in largely-unreactive samples.

\subsection{Tests to determine Class 1 explosives}

Series 3 tests are comprised of small-scale tests on the material: (a) impact sensitivity by drop hammer; (b) friction by BAM tester; (c) thermal stability at $75^{\circ} \mathrm{C}$; and (d) small-scale burning test. Series 6 tests includes a set of tests of the material packaged for shipment: (a) explosive initiation test of one package to see if deliberate stimulation by a detonator will set off an energetic reaction; (b) explosive initiation test of a stack of packages to see if reactions propagate from one package to the next; and (c) thermal test to see if exposure to a fire will set off an energetic reaction. If the Series 6(a) test shows that there is no damage to the exterior of the package, then the Series 6(b) test is waived. ${ }^{1}$

It was not necessary to conduct Series 6 tests on all explosives. We instead used the explosive most sensitive to initiation that we typically handle, PETN, for the Series 6 tests, and established a level that is non-reactive. Since our other explosives are less-easily initiated by a detonator or fire, they will pass the Series 6 tests when at the same level for which PETN is non-reactive, and they may therefore be certified by analogy as non-reactive in the Series 6 tests. ${ }^{*}$ The Series 3 tests, however, must be performed for each explosive mixed with clay at an explosive level of at least 4 weight percent.

\subsection{Details of Series 3 tests}

Series 3 tests are comprised of four small-scale tests on the material: (a) impact sensitivity by drop hammer; (b) friction by BAM tester; (c) thermal stability at $75^{\circ} \mathrm{C}$; and (d) small-scale burning test. 1

\footnotetext{
* There is ambiguity in the United Nations protocol. If the material in question was "manufactured with the view to producing a practical explosive or pyrotechnic effect," then the Series 3 and Series 6 tests are required. If not, a simpler Series 1 set of tests is required. We took the conservative approach that the waste must pass the more stringent Series 3 and Series 6 tests, although the waste was not "manufactured with the view to producing a practical explosive or pyrotechnic effect." This approach was required by the U.S. Department of Transportation for LLNL-developed explosive simulants and was adopted here as well.

- This certification by analogy was accepted by the U.S. Department of Transportation for LLNL-developed explosive simulants.
} 
Test 3(a) is the impact sensitivity test; the purpose is to measure the sensitivity of the material to an impact from a dropped weight. A $2.5 \mathrm{~kg}$ weight is dropped onto $35 \mathrm{mg}$ samples of the material from different heights and any reaction is detected. The reported value is the height in centimeters at which $50 \%$ of the drops result in a reaction. The test is documented further by Simpson. ${ }^{3}$ Typical heights for standard explosives are shown in Table 1. If the 50\%-go drop height is greater than that of dry RDX, the test result is negative and the material remains a candidate as a non-reactive material. If the 50\%-go drop height is less than or equal to that of dry RDX, the test result is positive and the material is considered reactive.

Table 1. Typical results from the LLNL Drop

Hammer Impact Sensitivity Test

\begin{tabular}{|c|c|}
\hline Explosive & Drop Hammer Result, cm \\
\hline PETN & $15 \pm 3$ \\
\hline RDX & $37 \pm 6$ \\
\hline HMX & $31 \pm 4$ \\
\hline Comp B-3 & $50 \pm 4$ \\
\hline TNT & $61 \pm 9$ \\
\hline TATB & $>177$ \\
\hline
\end{tabular}

Test 3(b) is the friction sensitivity test; the purpose is to measure the sensitivity of the material to frictional stimuli. A standard friction testing machine, the BAM machine, is specified by the UN and is used at LLNL. In this instrument, the material is rubbed between a rounded rod and a coarse porcelain plate while under load. An explosive reaction, as evidenced by loud report, crackling, spark, or flame) indicates a positive response at that load. The final reported value is the load or force needed to give one reaction in ten tests. Typical loads for standard explosives are shown in Table 2. The test is documented further by Simpson. ${ }^{4}$ If the load to give 1 reaction in 10 tests is greater or equal to $80 \mathrm{~N}$, the test result is negative and the material remains a candidate as a non-reactive material. If the load to give 1 reaction in 10 tests is less than $80 \mathrm{~N}$, the test result is positive and the material is considered reactive.

Table 2. Typical results from the LLNL Friction Sensitivity (BAM) Test

\begin{tabular}{|c|c|}
\hline Explosive & Load to give 1 reaction in 10 tests \\
\hline PETN & $60 \mathrm{~N}$ \\
\hline RDX & $120 \mathrm{~N}$ \\
\hline HMX & $120 \mathrm{~N}$ \\
\hline LX-17 (TATB/Kel-F) & $>360 \mathrm{~N}$ \\
\hline
\end{tabular}

Test 3(c) is the thermal stability test at $75^{\circ} \mathrm{C}$; the purpose is to measure the stability of the material when subjected to elevated temperatures. There are 
two versions of this test, uninstrumented and instrumented. If a material is thermally stable in the uninstrumented test, the instrumented test is not required; the instrumented test may be run in place of the uninstrumented test if desired. If in the test(s) the material is thermally stable, it remains a candidate as a non-reactive material. A material that is not thermally stable is considered reactive.

In the uninstrumented test, a 50 gram sample is placed in a beaker, covered, and held in an oven at $75^{\circ} \mathrm{C}$ for 48 hours or until reaction or explosion takes place, if sooner). If there is no ignition or explosion, and no evidence of thermal instability (i.e. fuming, decomposition, significant mass loss), the material is considered thermally stable.

In the instrumented test, a 100-gram sample is placed in a container. An inert sample of equal mass is placed in a second identical container. Both containers are placed in an oven at $75^{\circ} \mathrm{C}$ and held for 48 hours (or until reaction or explosion takes place, if sooner). The temperatures of both containers are monitored during this time, to allow measurement of any exothermic reaction and resultant selfheating in the sample. At the end of the test, the sample is inspected for any sign of reaction. If there is no ignition or explosion and no significant self-heating, the material is considered thermally stable.

Test $3(d)$ is the small-scale burning test; the purpose is to determine the response of the material to a fire. A 125-gram sample is placed on top of kerosene-soaked sawdust, which is then ignited. The fire is observed visually. The test must be conducted in triplicate. If the material does not burn, or simply burns along with the kerosene-sawdust, it passes this test and remains a candidate as non-reactive material. If it explodes, it is considered reactive. ${ }^{\psi}$

\subsection{Details of Series 6 tests}

Series 6 tests are designed to test the material in the configuration in which it will be shipped. The tests measure the response of the packaged material to an internal explosion and to an external fire. ${ }^{1}$

Test 6(a) measures the response of the packaged material to an internal explosion. A standard detonator ${ }^{1}$ is placed near the center of the packaged material and fired. The material is classified depending on the severity of the ensuing reaction. If there is no reaction, the material remains a candidate as a non-reactive material. Triplicate testing is required.

\footnotetext{
"In the previous revision of Reference 1 (Rev. 1), Test 3(d) was defined to be run with 125 grams of material, in triplicate. In the current revision of Reference 1 (Rev. 2), Test 3(d) is defined as two runs with 10 grams of material and two runs with 100 grams. Our tests followed the specifications in Rev.1, which are in any case more stringent than those in Rev.2.
} 
Test 6(b) is like Test 6(a), but with several packages of the material. The purpose is to measure the propagation of reaction from one container to another. If Test 6(a) shows no external damage to the package, then Test 6 (b) is waived.

Test 6(c) measures the response of the packaged material to an external fire. Three packages of the material are placed as close together as possible, and subjected to an external fire. The fire must be hot enough and of sufficient duration to consume all the explosive. The classification of the material depends on the severity of the response, ranging from mass explosion of the package to no hazardous effects at all. If there are no hazardous effects, the material remains a candidate as a non-reactive material.

\subsection{Sample preparation}

The clay used was a granulated absorbent, called "All Purpose Absorbent" containing "natural earth product," made by the Excel-Mineral Corporation of Goleta, CA. The PETN used for Series 3 and 6 tests was LLNL lot B-509, approximately 19 years old. The other explosives used in Series 3 tests were generic samples that we had in stock.

To mix the explosive and clay, the components were blended by hand in a tray or in a roll mill, and then placed in a static-free polyethylene bag. Additional mixing was done immediately before loading for the Series 6 tests, by hand-manipulating the plastic bag containing the sample. For mixtures involving pure explosive with no binder, the explosive was wetted with $10 \%$ water by weight to desensitize it and to reduce dust formation.

\subsection{Configuration of material in shipping container, for Series 6 tests}

The Series 6 tests involve the material packaged for shipment. The configuration used in these tests was a $9 \mathrm{~kg}(20 \mathrm{lb}$.) mass of the surrogate waste contained in a plastic bag; the bag was placed in the center of a UNIA2 55-gallon drum equipped with a carbon filter, with a layer of clay surrounding it and occupying the remainder of the volume as dunnage. This dunnage is about 8 inches thick on the sides, and about 14 inches thick on top and bottom.

\subsection{Results of Series 3 Tests}

Table 3 summarizes the results of the Series 3 tests.

The major explosive constituents considered are PETN, HMX, RDX, TATB, CL-20, and TNT. We tested each of these pure explosives, diluted with clay, 
to establish that the diluted pure explosives are non-reactive in the Series 3 tests. We tested pure PETN diluted with clay to establish that diluted pure PETN is non-reactive in the Series 6 test. Since all the other listed explosives are less sensitive to heat and shock than PETN, the others pass the Series 6 test by analogy.

For explosives formulated from one of above constituents and an unreactive binder such as Viton A, Kel-F 800, or Estane, the formulated explosive will be less reactive than the pure constituent. Therefore, the data for the pure constituent are sufficient to qualify debris containing the formulation as well as the pure constituent. These explosive formulations are listed in Table 3, with data shown only for the pure constituent.

For explosives formulated with an energetic liquid, binder, or plasticizer, the formulated explosive may be more or less reactive than the pure constituent. Therefore, the actual formulation must be tested in the Series 3 protocol. Formulations for which this has been done are listed in Table 3.

Many pure explosives, undiluted with clay, will pass some of the Series 3 tests; the presence of clay provides a further safety margin. These explosives were tested in pure form, as shown in Table 3 , since for many of them data were already available.

In addition to the Series 3(c) thermal stability test, we performed the LLNL Chemical Reactivity Test ${ }^{5}$ on all samples. In this test, a 0.25 gram sample is held at $80^{\circ} \mathrm{C}$ or $120^{\circ} \mathrm{C}$ for 22 hours, and the extent of decomposition determined by analysis of the offgas. Samples that produce less than 1 standard cubic centimeter of gas are considered thermally stable; this represents about $0.2 \%$ decomposition, and is the amount of gas produced by PBX-9404 (94\% HMX, 3\% nitrocellulose, 3\% tris-ß-chloroethylphosphate). All of the pure explosives were stable at $120^{\circ} \mathrm{C}$. All of the formulated explosives were stable except RX-08-HD, which was stable at $80^{\circ} \mathrm{C}$. 
Table 3. Results of Series 3 test results.

\begin{tabular}{|c|c|c|c|c|}
\hline Explosive & $\begin{array}{l}\text { 3(a) Impact } \\
\text { sensitivity } \\
\text { result, cm } \\
(>37=\text { pass })\end{array}$ & $\begin{array}{c}\text { 3(b) Friction } \\
\text { sensitivity } \\
\text { result, } N \\
(>80=\text { pass })\end{array}$ & $\begin{array}{c}\text { 3(c) Thermal } \\
\text { stability } \\
\text { result }\end{array}$ & $\begin{array}{l}\text { 3(d) Small- } \\
\text { scale } \\
\text { burning } \\
\text { result }\end{array}$ \\
\hline $\begin{array}{l}\text { PETN } \\
\text { LX-16 }\end{array}$ & $>177(11 \%)$ & $>360(11 \%)$ & $\begin{array}{c}\text { pass }(4 \%) \\
(0.2 \% \text { mass loss })\end{array}$ & pass $(4 \%)$ \\
\hline $\begin{array}{l}\text { HMX } \\
\text { LX-04 } \\
\text { LX-07 } \\
\text { LX-10 } \\
\text { LX-11 } \\
\text { LX-14 }\end{array}$ & $168(15 \%)$ & $120(100 \%)$ & $\begin{array}{l}\text { pass }(15 \%) \\
(<0.2 \% \text { mass loss })\end{array}$ & pass $(15 \%)$ \\
\hline PBX-9404 & $168(15 \%)$ & $250(100 \%)$ & $\begin{array}{c}\text { pass }(15 \%) \\
(<0.2 \% \text { mass loss })\end{array}$ & pass $(15 \%)$ \\
\hline PBX-9501 & $>177(15 \%)$ & $360(15 \%)$ & $\begin{array}{c}\text { pass }(15 \%) \\
(<0.2 \% \text { mass loss })\end{array}$ & pass $(15 \%)$ \\
\hline RX-08-HD & $168(15 \%)$ & $190(100 \%)$ & $\begin{array}{c}\text { pass }(15 \%) \\
(0.5 \% \text { mass loss })\end{array}$ & pass $(15 \%)$ \\
\hline $\begin{array}{l}\text { RDX } \\
\text { PBX-9407 }\end{array}$ & $>177(15 \%)$ & $120(100 \%)$ & $\begin{array}{l}\text { pass }(15 \%) \\
(<0.2 \% \text { mass loss })\end{array}$ & pass $(15 \%)$ \\
\hline $\begin{array}{l}\text { TATB } \\
\text { LX-17 } \\
\text { PBX-9502 }\end{array}$ & $>177(100 \%)$ & $>360(100 \%)$ & $\begin{array}{c}\operatorname{pass}(15 \%) \\
(<0.2 \% \text { mass loss })\end{array}$ & pass $(15 \%)$ \\
\hline $\begin{array}{l}\text { CL-20 } \\
\text { LX-19 }\end{array}$ & $161(15 \%)$ & $>360(15 \%)$ & $\begin{array}{l}\text { pass }(15 \%) \\
(4.5 \% \text { mass loss })\end{array}$ & pass $(15 \%)$ \\
\hline TNT & $>177(15 \%)$ & $360(100 \%)$ & $\begin{array}{c}\text { pass }(15 \%) \\
(<0.2 \% \text { mass loss })\end{array}$ & pass $(15 \%)$ \\
\hline
\end{tabular}

Data are listed for pure PETN, HMX, RDX, TATB, CL-20, and TNT mixed with clay, showing that these pure explosives are non-reactive when diluted by clay (weight percent explosive in the explosive/clay sample is shown in parentheses, all are greater than or equal to 4 weight percent). Formulations with these constituents and an unreactive binder are shown with the pure constituents - these do not require separate testing, since the formulations are less reactive than the pure constituent. Formulations that include other energetic component are listed separately, along with Series 3 test data, since they may be more or less reactive than the pure constituent. 


\subsection{Results of Series 6 Tests}

We chose PETN as the explosive to use in the Series 6 tests, since it is the most sensitive explosive to heat and shock initiation of those listed in Table 3. As described below, we determined the maximum concentration of PETN in clay that is non-reactive in the 6(a) initiation test, and then tested that concentration in the 6(c) fire test.

For all Series 6 tests, the PETN/clay samples were packaged in a UNIA2 55gallon shipping container that is qualified as a low-level radioactive waste shipping container. The drum lid was equipped with a carbon filter to allow air to move in and out of the drum due to temperature changes. A sample mass of $9.1 \mathrm{~kg}$ was placed in a plastic bag in the approximate center of the shipping drum; the remainder of the drum volume was filled by pure clay without explosive added.

\subsection{Results of 6(a) Initiation Test}

We first carried out the Series 6(a) test that measures the response of the packaged material to an internal explosion. A standard detonator containing $0.6 \mathrm{~g}$ PETN is placed near the center of the packaged material and fired; we used SE-1 detonators. The material is classified depending on the severity of the ensuing reaction. If there is no reaction (as shown by no visible external damage or deformation of the container following the test), the material is non-reactive in this test. Triplicate testing is required. To provide an additional margin of safety, we tested each sample that showed no reaction a second time, using a detonator plus booster pellet of 1.2 grams; this provided a severe overtest of the safety of the material.

Previous tests at LLNL had shown that $11 \%$ PETN in clay gave a violent response in the 6(a) test. To verify that PETN at very low levels is not sensitive to initiation, we first established in a small-scale (7-gallon) test that PETN at 4 weight percent was non-reactive. We then tested sequentially lower levels of PETN in clay, starting at $8 \mathrm{wt} \%$ and working our way down to the point where three tests showed no reaction. The test sequence is shown in Figure 1.

The results of the tests are listed and described below. Also included are photographs of some of the test results. 


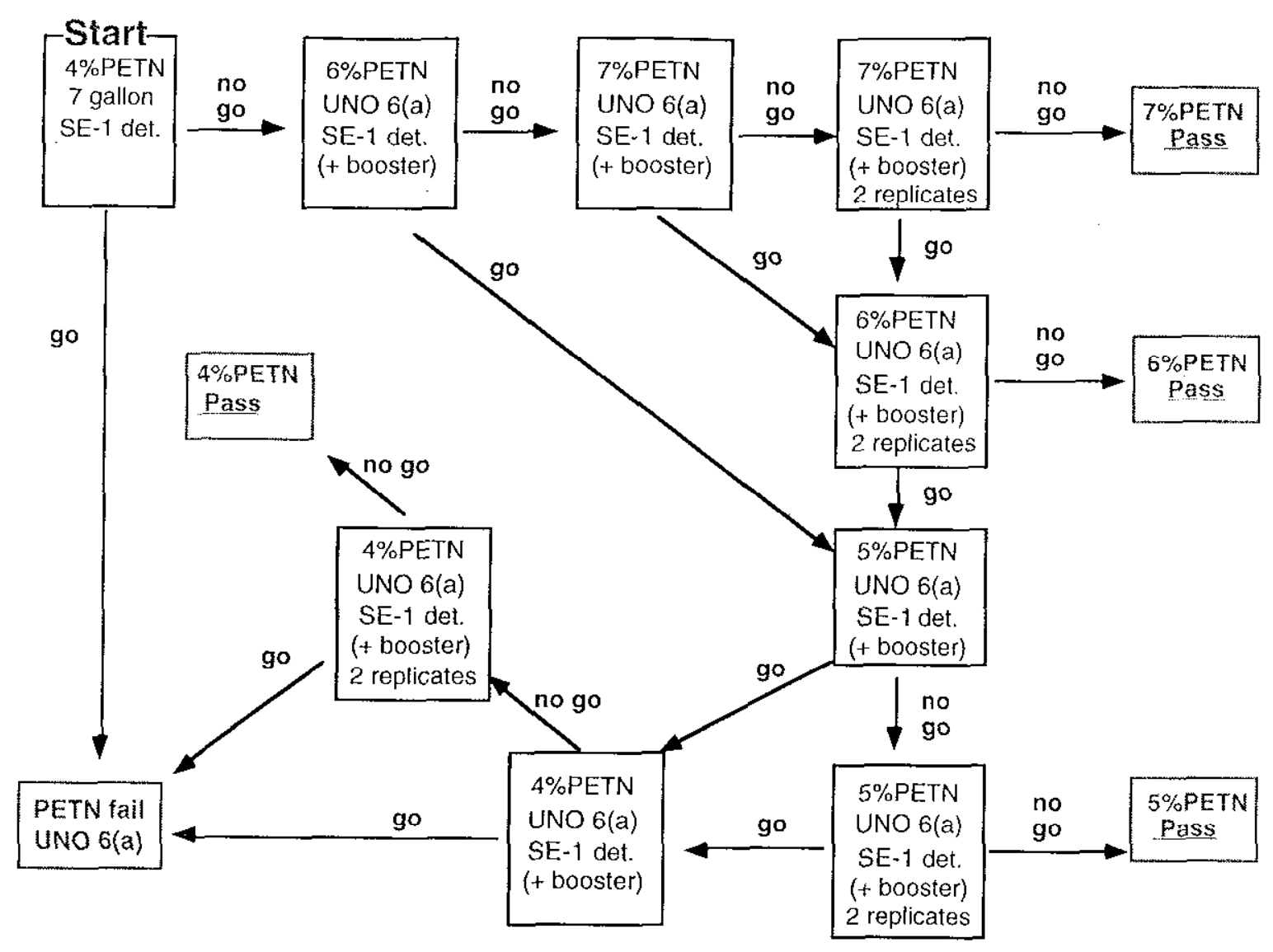

Figure 1. Plan for establishing maximum level of PETN allowable in nonreactive material, as defined by the UNO Series 6(a) test. Tests labeled as UNO 6(a) were performed with material packaged for shipment. The test labeled as 5 gallon had the PETN/clay mixture in a 7-gallon container, and was run as a low-cost screening test before turning to the more-expensive tests with large amounts of material in 55-gallon drums. 
4.1.1 11\% PETN / clay, 6(a) test: Violent explosion, apparent complete reaction, with detonator only. FAIL

4.1.2 4\% PETN / clay, 7-gallon test: No reaction with detonator only. Lid blew off with booster pellet (probably effect of booster pellet).

APPEARS NON-REACTIVE

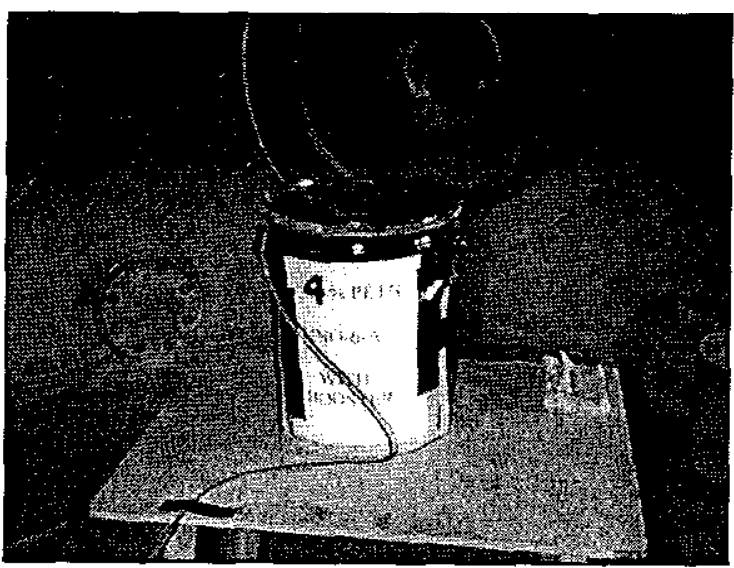

Figure 2a. Pre-test setup

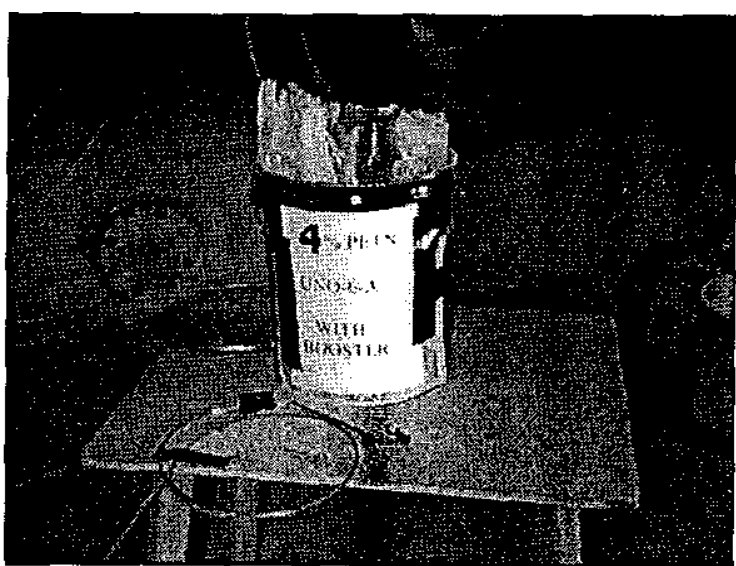

Figure 2b. Post test results

4.1.3 8\% PETN / clay, 6(a) test: Violent explosion, apparent complete reaction, with detonator only. FAIL

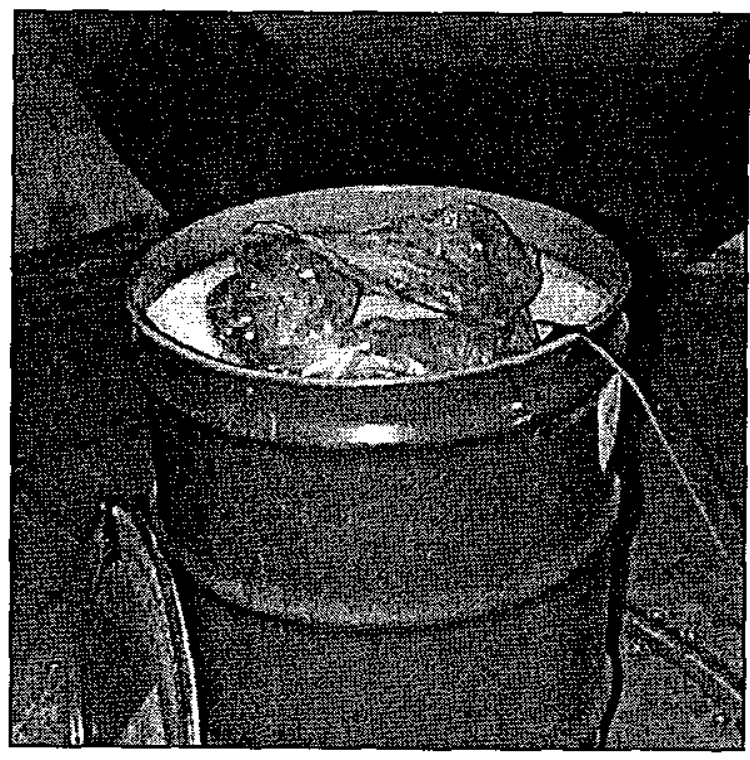

Figure 3a. Pre-test setup - before lid is put on

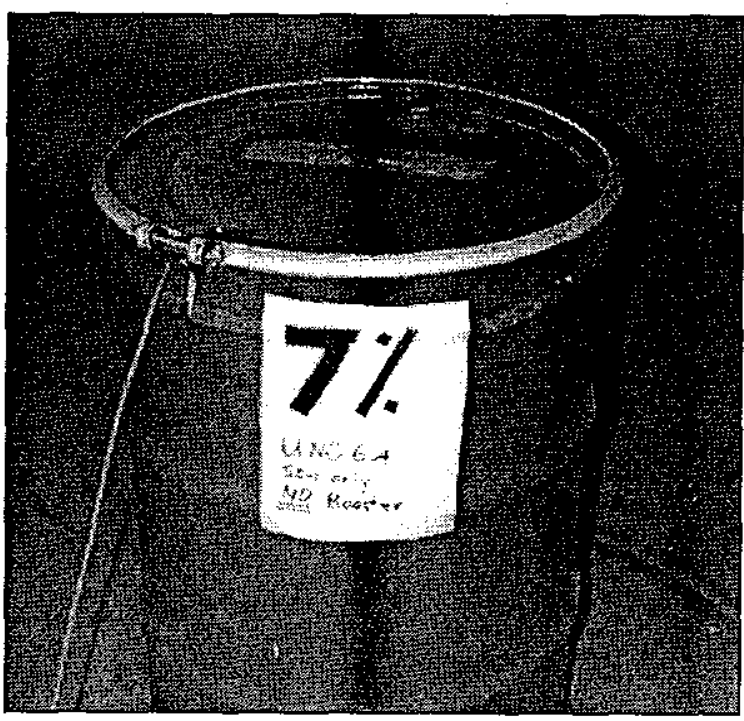

Figure 3b. Pre-test setup with lid in place (this photo for $7 \%$ test) 


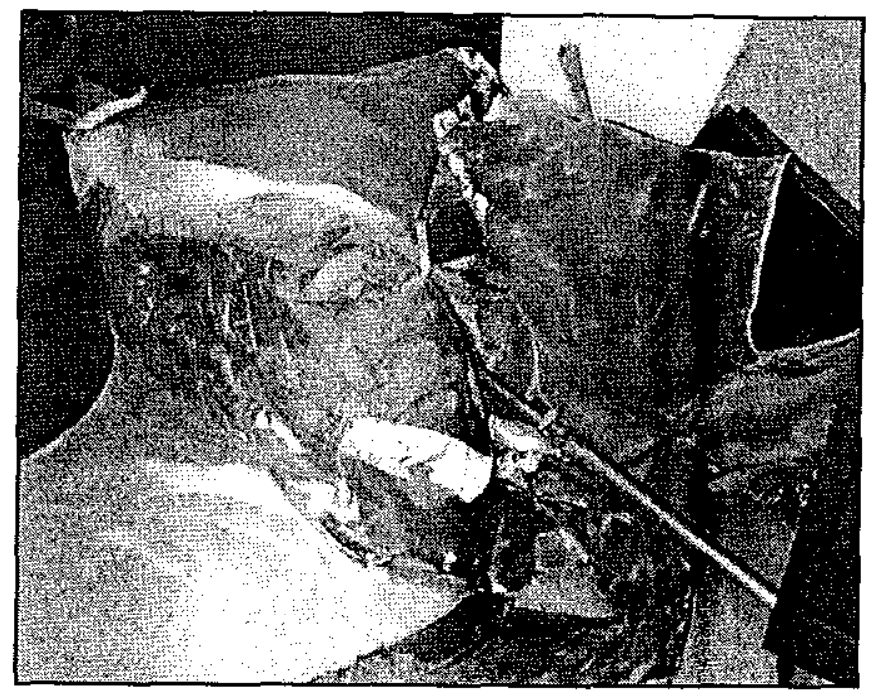

Figure 4. Post-test appearance of barrel - 8\% PETN

4.1.4 6\% PETN / clay, 6(a) test: No reaction with detonator. Mild reaction with detonator plus booster - lid blew off, barrel slightly bulged. Contents not expelled. PASS
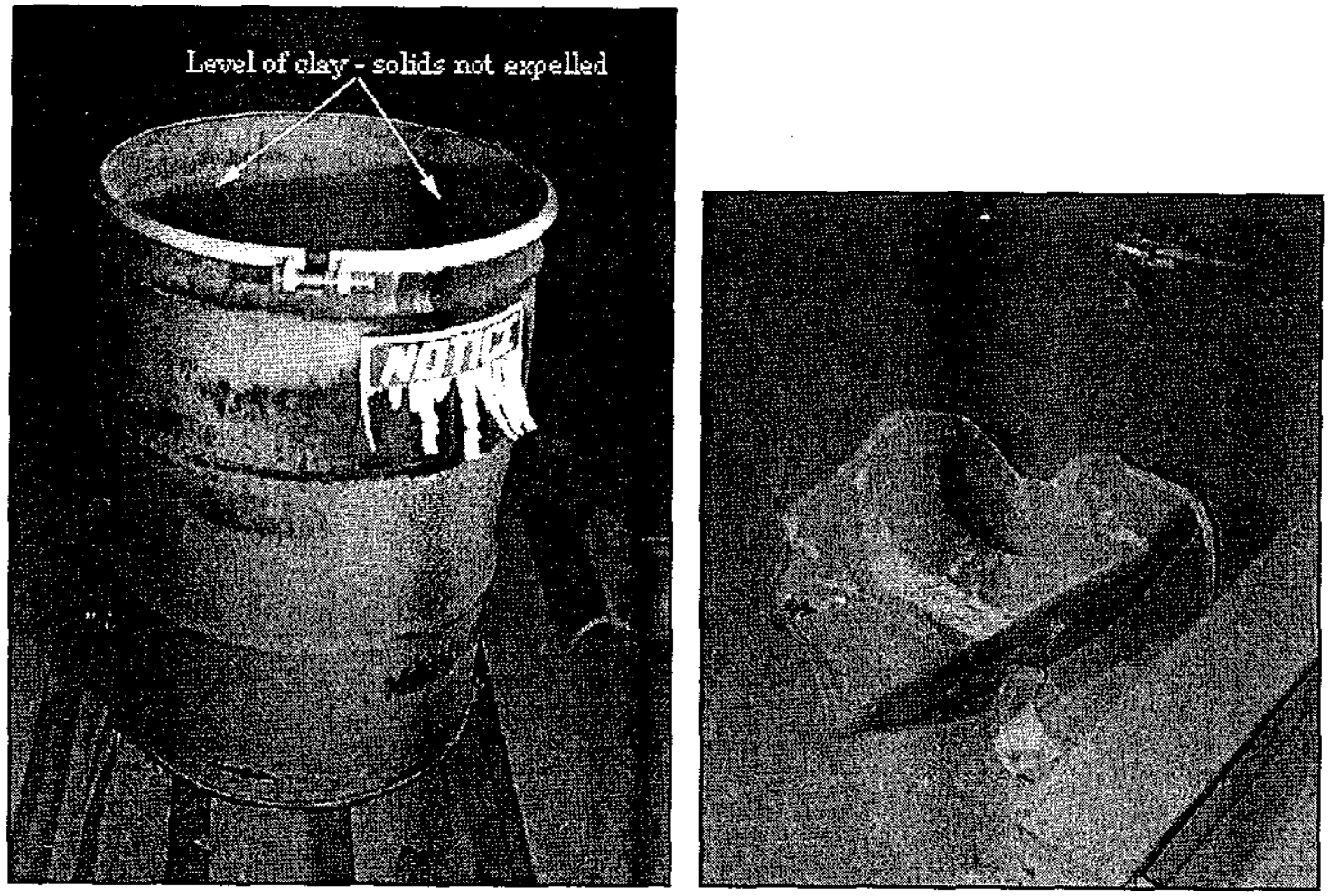

Figure 5a. Post-test appearance of barrel

Figure 5b. Post-test appearance of lid 
4.1.5 7\% PETN / clay, 6(a) test: Violent explosion, apparent complete reaction, with detonator only. FAIL

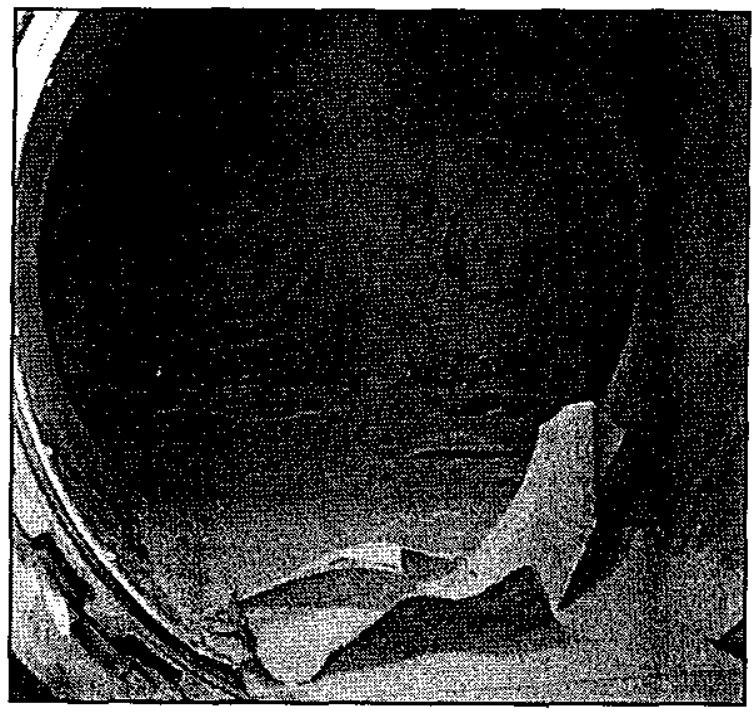

Figure 6a. Post-shot - remains of barrel are seen close to camera

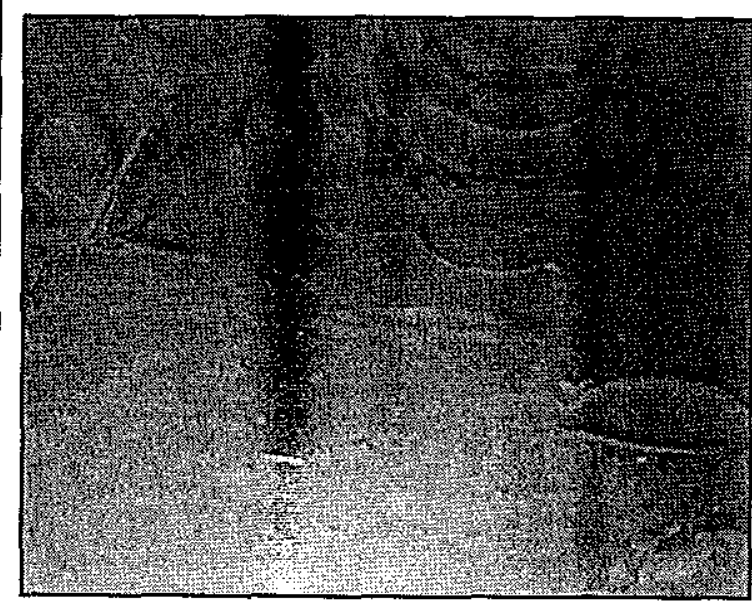

Figure 6b. Post-shot: pulverized clay covers tank; lid is at right

4.1.6 6\% PETN / clay, 6(a) test: Very delayed reaction with detonator only. No reaction for 5-10 minutes, then lid blew off and barrel bulged. Cause could not be established - possible detonator malfunction. This could be considered a pass, but we deemed it a NO TEST.

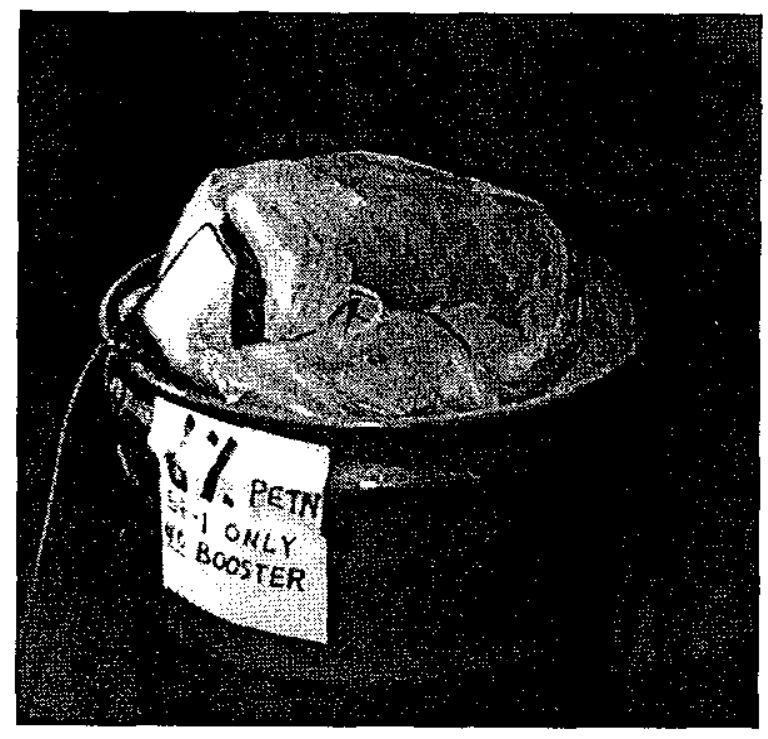

Figure 7a. Barrel after lid blew off. Very minor disruption of contents.

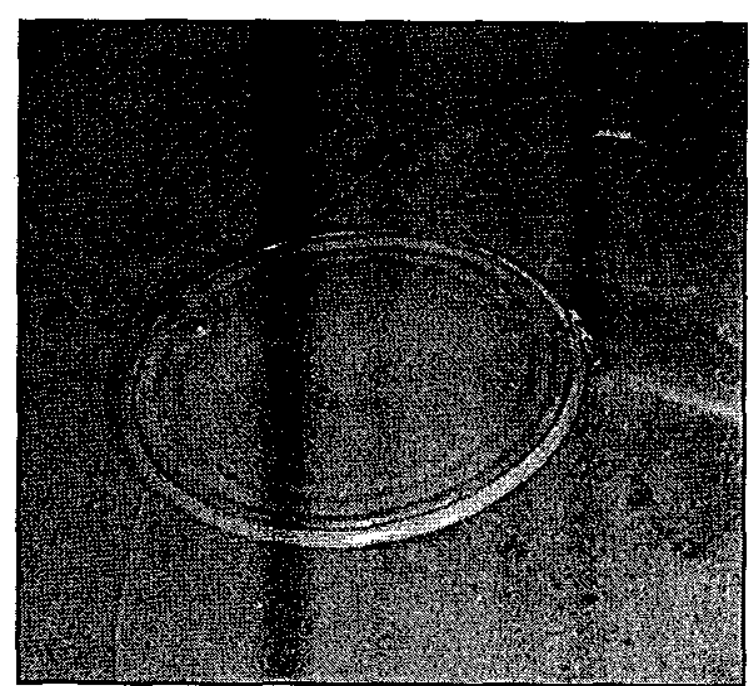

Figure $7 \mathrm{~b}$. Barrel of lid resting on tank floor. It was not deformed. 
Following this test, we installed pressure gauges on the barrels to detect any late-time pressure excursions.

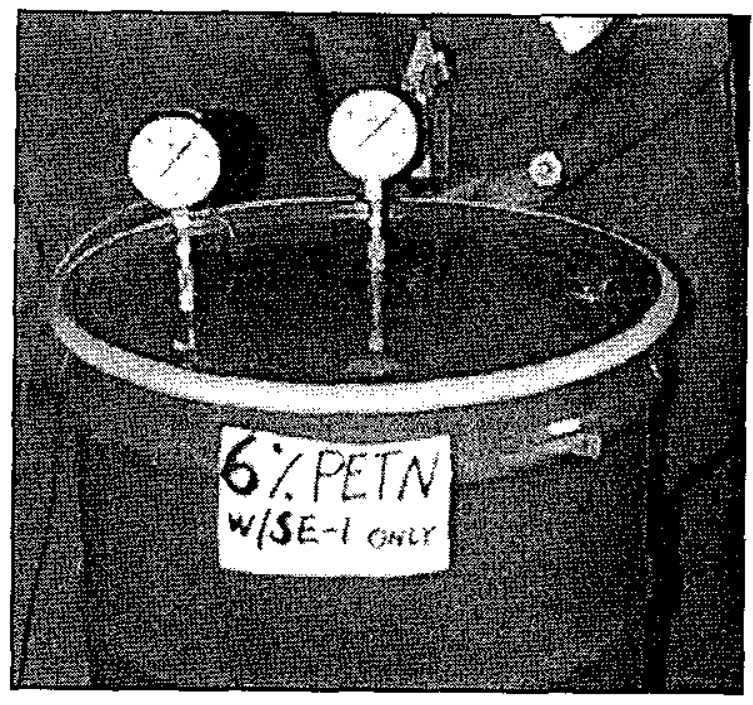

Figure 8a. Barrel equipped with pressure gauges for subsequent tests

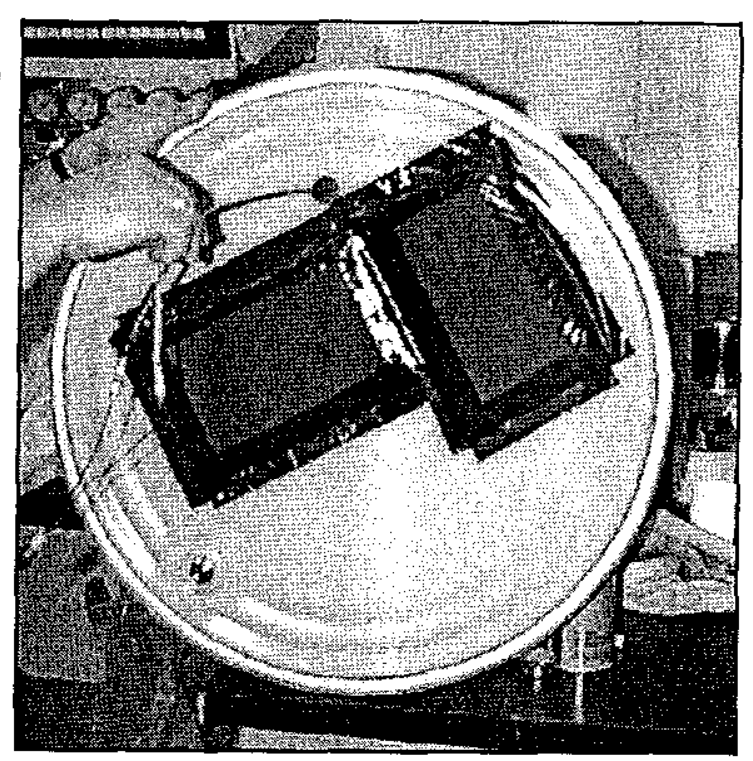

Figure 8b. Filters mounted on barrel lid to keep dust out of gauges

4.1.7 6\% PETN / clay, 6(a) test: Violent explosion with detonator only. FAIL

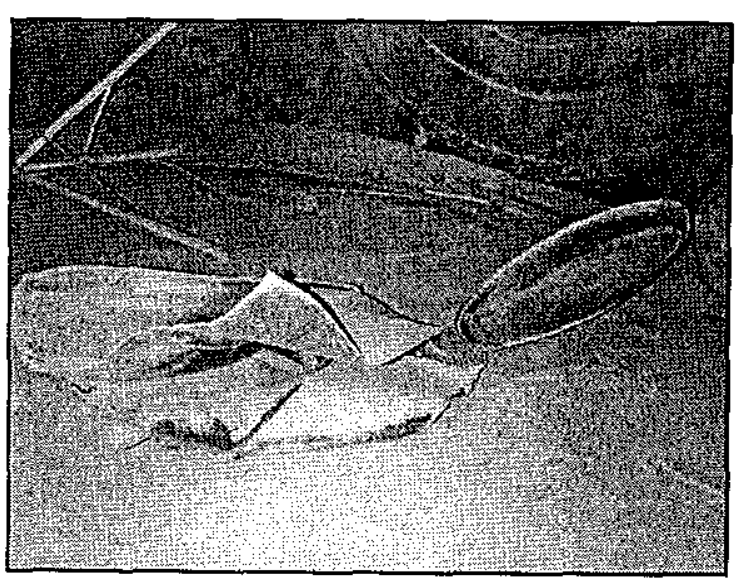

Figure 9a. Post-test appearance of barrel

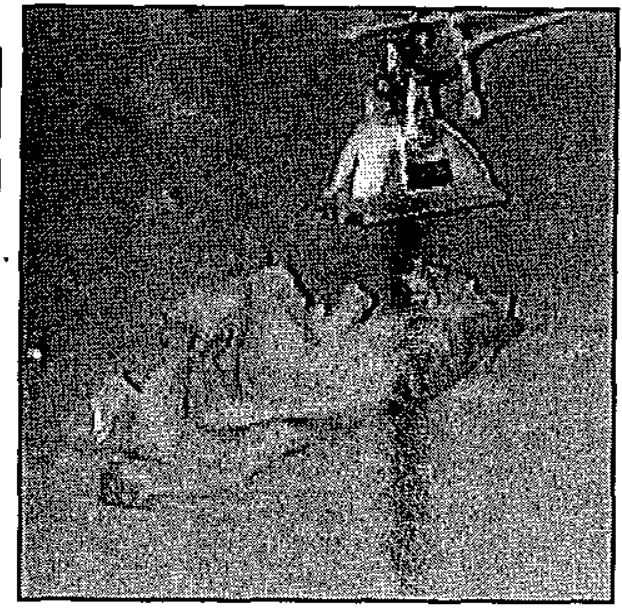

Figure 9b. Post-test appearance of lid

4.1.85\% PETN / clay, 6(a) test: No reaction, with detonator only and with detonator and booster. PASS

No photographs 
4.1.9 5\% PETN / clay, 6(a) test: No reaction, with detonator only and with detonator and booster. PASS

No photographs

4.1.105\% PETN / clay, 6(a) test: Mild explosion, bulging barrel and blowing off lid. 10-20\% of barrel contents was expelled. FAIL

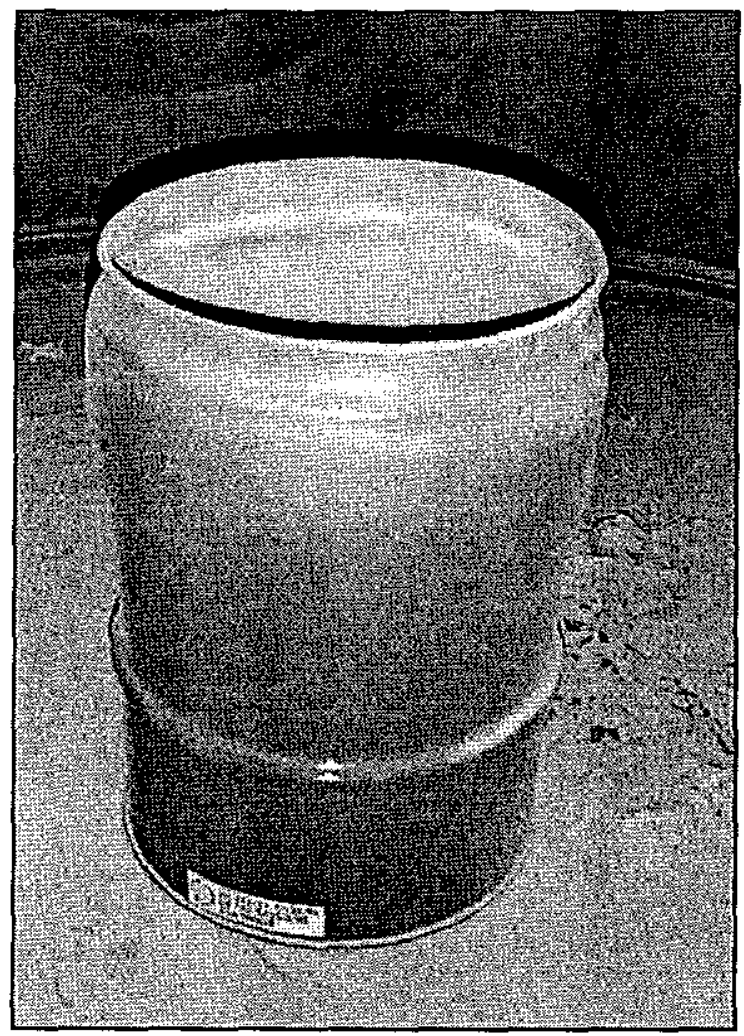

Figure 10a. Post-test bulged barrel. Clay is below visible level, indicating significant expulsion of contents

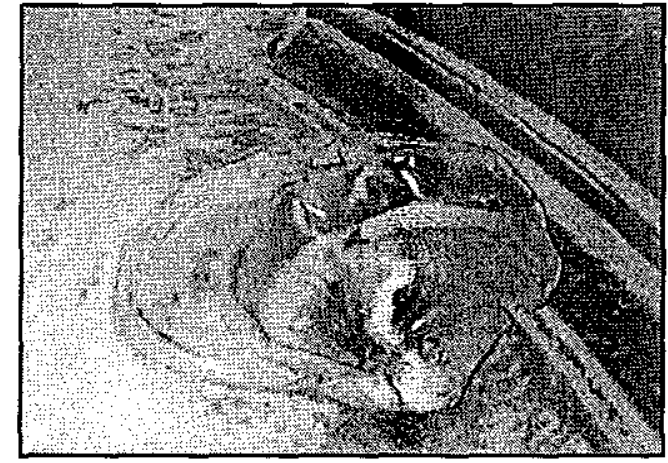

Figure 10b. Barrel lid post-test

4.1.11, 4.1.12, 4.1.13 4\% PETN / clay, 6(a) test: No reaction, with detonator only and with detonator and booster. PASS

The three 4\% PETN tests were run simultaneously. The lack of reaction with the three tests with booster pellets confirmed the non-reactivity of this composition. 

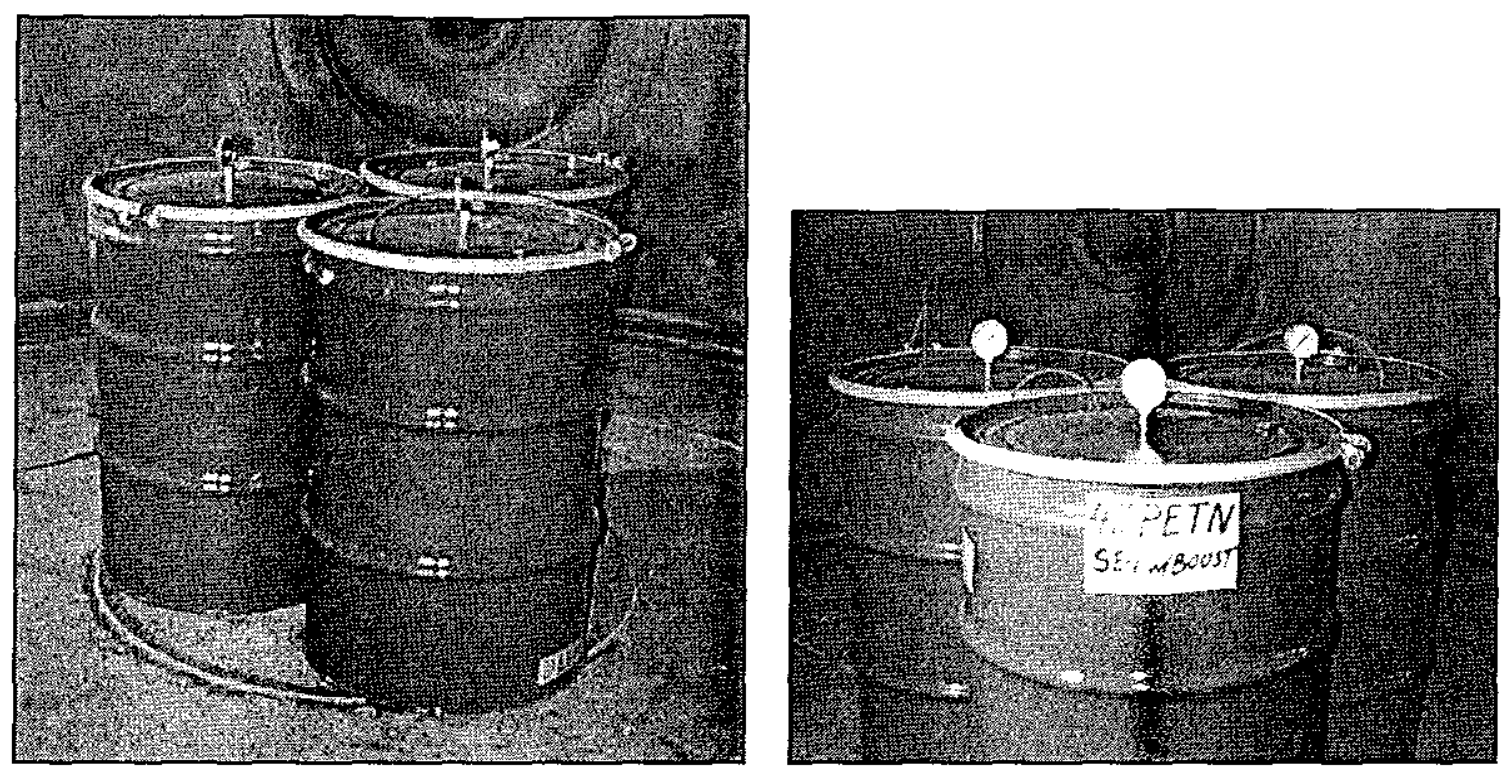

Figure 11a, b. Pre-test and post-test appearance of barrels containing 4\% PETN / clay mixtures

The actual testing pathway that we followed is summarized below:

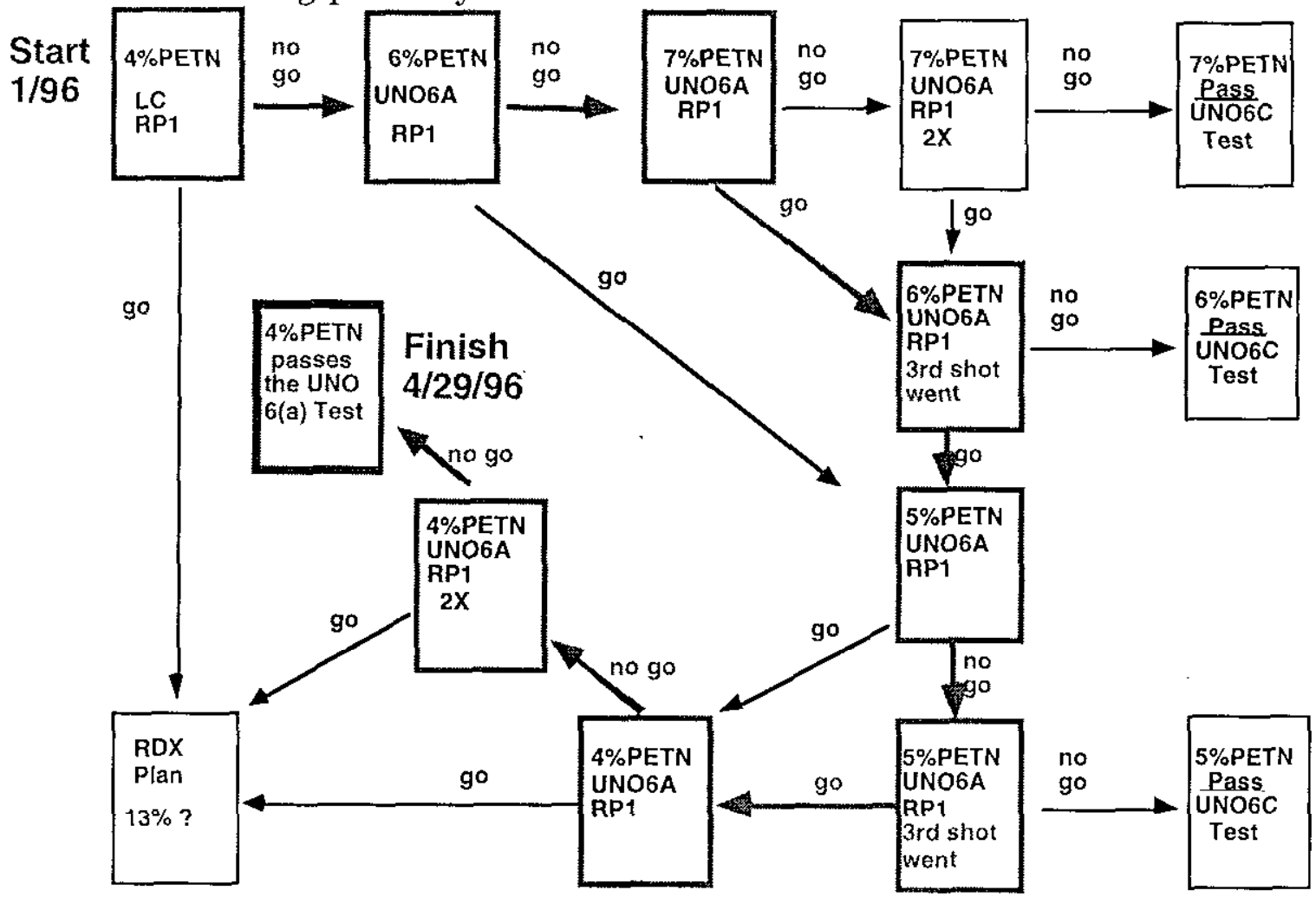

Figure 12. Testing path followed to establish maximum level of PETN allowable in non-reactive material, as defined by the UNO Series 6(a) test. Tests at $6 \%$ and $5 \%$ PETN showed no reaction on the first two tests, but did show reaction on the third test of the series 


\subsection{Results of 6(c) Fire Test}

The Series 6(c) Fire Test was performed only on the 4\% PETN / clay mixture that passed the Series 6(a) test. We first conducted two preliminary tests, one to determine that the test configuration would provide sufficient heating to fully decompose the PETN, and a second test to see if the gases released by the PETN undergoing thermal decomposition would be vented from the barrel fast enough to prevent rupture of the barrel. The final Series 6(c) test was performed on three containers, as required by the testing protocol. We tested all three simultaneously, as was done on the final 6(a) test.

Before conducting the actual test, we made two preliminary tests, one to test that the contents of the barrel would be heated hot enough that the PETN would decompose, and another to determine if the flow rate through the filtered vent on the barrel would be sufficient to release the product gases as the PETN thermally decomposed.

\subsubsection{Preliminary heating test}

In the preliminary heating test, we heated a barrel containing only clay, in the same configuration that the final test was to be run. The purpose was to ensure that the contents would be heated sufficiently to decompose the PETN $-200^{\circ} \mathrm{C}$ based on thermal analysis data. ${ }^{6}$ We embedded thermocouples at several locations inside the clay to monitor the heating. The results are shown in Figure 13. From the results, we see that the PETN must be located within 5 inches of the bottom of the barrel to ensure that the temperature rises high enough to decompose PETN. 


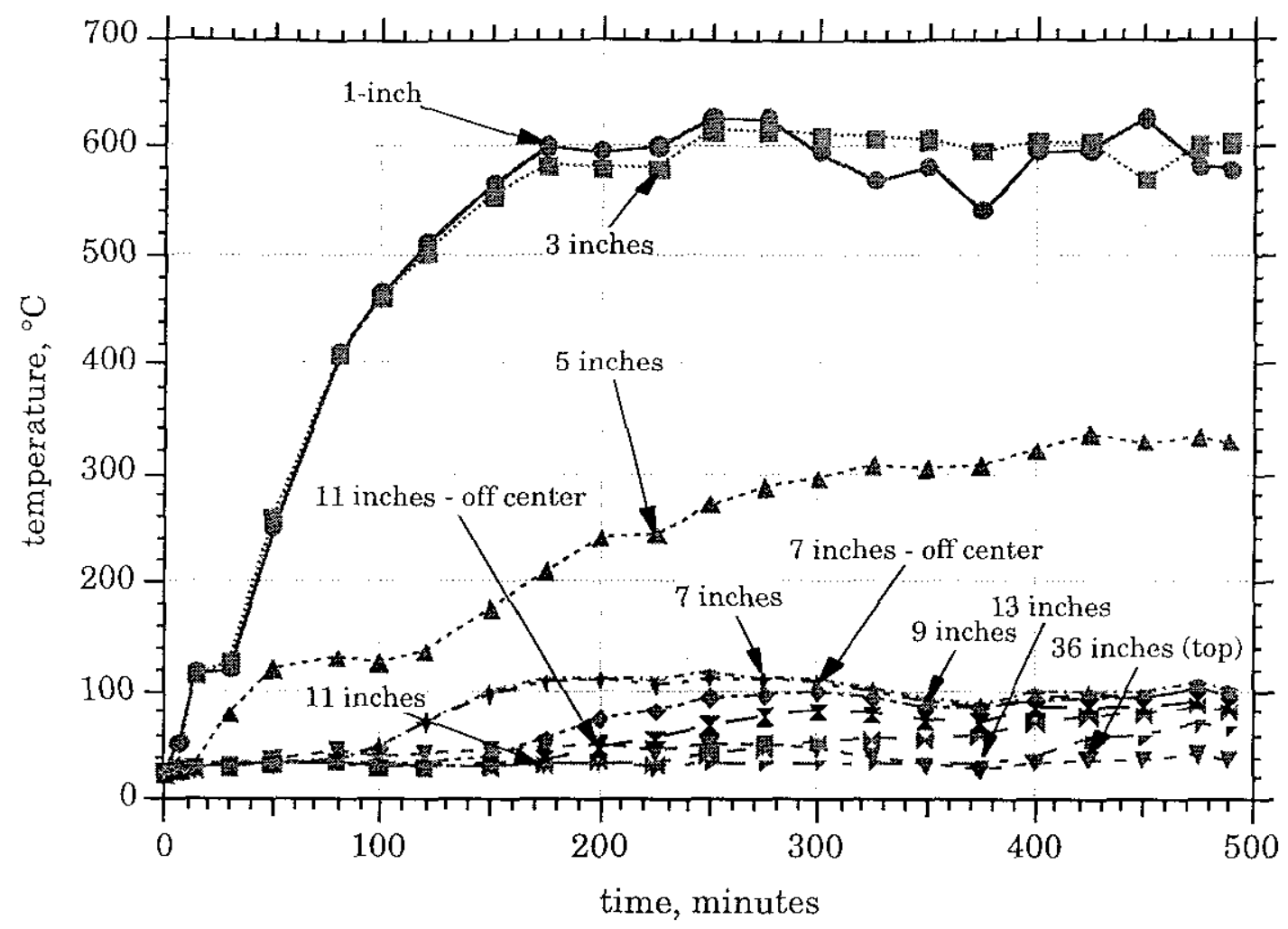

Figure 13. Temperature data from preliminary heating test with pure clay in final test configuration. Labels show the distance of the thermocouple from the bottom of the barrel. All thermocouples were on the center axis except those noted, which were midway between center and edge of barrel.

There are two significant implications of the data in Figure 13. First, in order to conduct the Series 6(d) test such that the PETN is decomposed, the PETN/clay sample had to be located at the bottom of the barrel. (In the actual test, we placed a 1-inch layer of clay on the bottom of the barrel, and spread the 20-1b bag of PETN/clay across that to form a layer a few inches deep.) The second implication is that, in the actual shipping configuration where the waste clay mixed with explosive is in a bag in the center of the barrel with pure clay on all sides, it is virtually impossible for the waste to be heated above $100^{\circ} \mathrm{C}$. Therefore, the shipping configuration provides sufficient thermal insulation to protect the internal contents from the effect of a fire.

\subsubsection{Test of flow rate through vent filter}

The Series 6(c) test requires that the explosive component be until it thermally decomposes, in the shipping configuration. When PETN decomposes, it produces about 35 moles of gas per kilogram of PETN, based on CHEETAH. 7 The final test configuration contains 360 grams of PETN, and therefore produces 12.6 moles or 2800 std liters of gas. Roughly half of 
the shipping container volume is gas-filled, so the free volume for gas expansion is 27.5 gallons or about 100 liters. Therefore, if the gas released by thermal decomposition of PETN were retained in the container, the pressure would rise to about 28 atmospheres, certainly enough to rupture the barrel and cause failure of the test. The presence of a vent equipped with a carbon frit filter will prevent this by release of the gas as it is produced, if the flow rate through the carbon frit is sufficiently high. Before running the Series 6 (c) test, we measured the flow rate through the carbon frit to ensure that it was indeed high enough.

The rate of gas flow through a frit is proportional to the pressure differential driving the flow - for this case where the exit pressure is one atmosphere, the driving force is the gauge pressure inside the barrel. The loss of mass from the barrel during gas flow results in decreasing pressure. This can be expressed as:

$$
\text { mass flow }=-\mathrm{V} \frac{\mathrm{dP}}{\mathrm{dt}}=\mathrm{KP}
$$

where mass flow $=$ psig-liters; $\mathrm{V}=$ barrel volume, $\mathrm{L} ; \mathrm{P}=$ pressure inside barrel, psig, $\mathrm{t}=$ time, seconds, and $\mathrm{K}=$ flow constant for carbon frit, liters/s. If we know the flow constant for the frit, $\mathrm{K}$, we can determine if the gas flow through it will be sufficiently rapid to avoid rupture of the barrel during PETN decomposition.

To determine the flow constant of the carbon frit, we filled a barrel (equipped with a frit) with air to an elevated pressure, and then recorded the pressure-time history as the gas flowed out through the frit; the barrel contained 5 bags of clay to simulate the volume as it would be loaded with waste. We integrate Eq.(1) to get:

$$
\ln (\mathrm{P})=-\frac{\mathrm{K}}{\mathrm{V}} \mathrm{t}
$$

Therefore, a plot of $\ln (\mathrm{P})$ vs time should give a straight line with slope $-\mathrm{K} / \mathrm{V}$. Data and linear fits are shown in Figure 14 for initial pressures of 5, 10, and $15 \mathrm{psig}$. The data are consistent, with a slope essentially constant at $-0.02 \mathrm{~s}^{-1}$. With the effective barrel volume of 100 liters, the flow constant $\mathrm{K}$ for the carbon frit is $\approx 2$ liters/sec. 


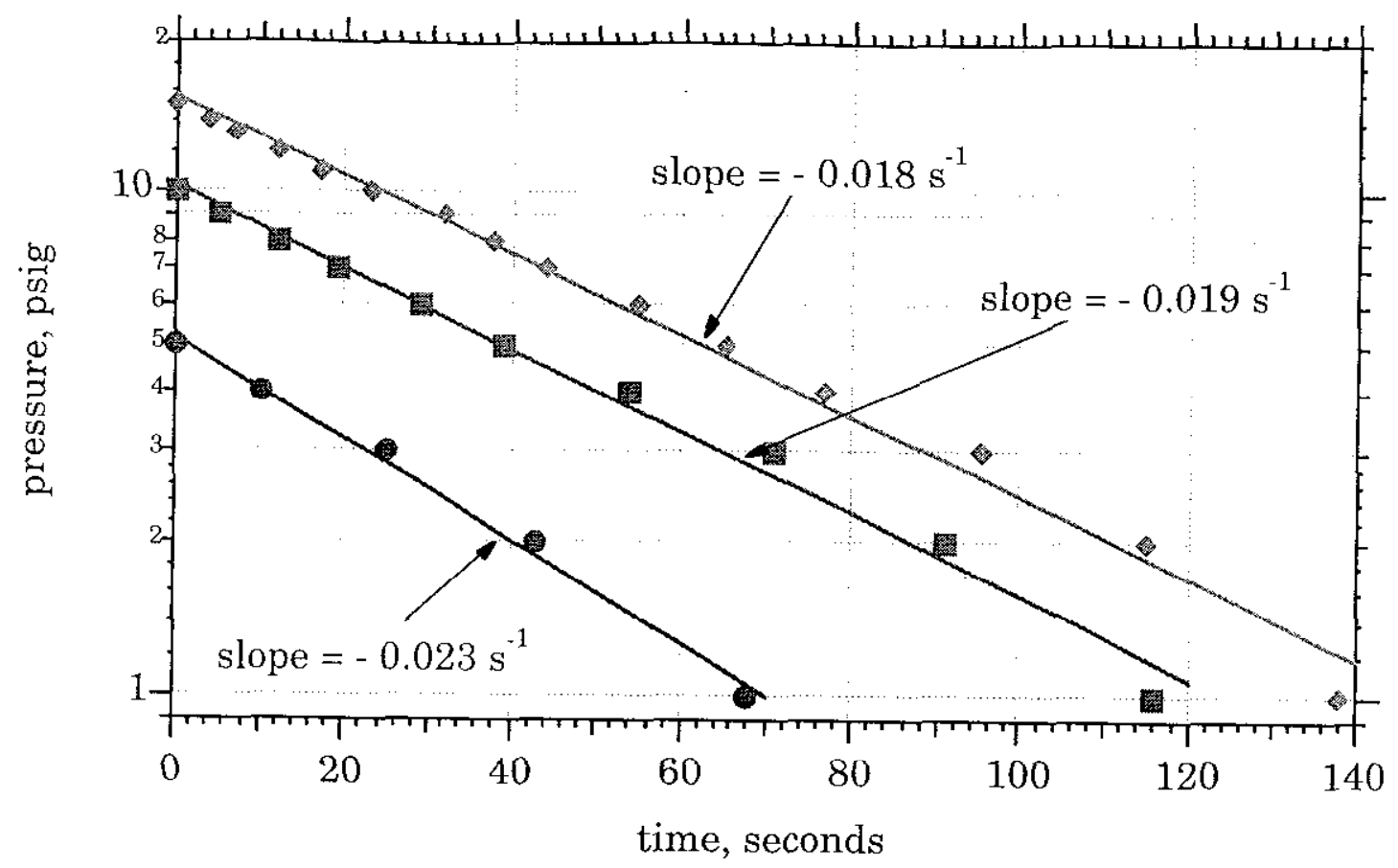

Figure 14. Pressure data from vent rate tests with carbon frit in shipping container, from initial pressures of 5, 10, and 15 psig. Slopes shown are from least-squares fit of the data in the form of Eq.(2).

With this flow constant, we can now calculate the maximum pressure in the barrel, for an assumed decomposition rate of PETN, $R$, mole/s. If we express mass flows in liter-atm/sec, the flow into the barrel is:

$$
\text { mass flow in }=R(\mathrm{~mole} / \mathrm{s}) \times 22.4(1-\mathrm{atm} / \text { mole }) \quad \text { Eq.(3) }
$$

and the mass flow out of the barrel is:

$$
\text { mass flow out }=\mathrm{K}(\mathrm{l} / \mathrm{s}) \mathrm{P}(\mathrm{psi}) \times 1 \mathrm{~atm} / 14.7 \mathrm{psi} \quad \text { Eq.(4) }
$$

Once PETN decomposition starts, the pressure in the barrel will increase until the mass flow rates in and out are equal, or until Eqs.(3) and (4) are equal. We can thus calculate the maximum pressure as:

$$
\mathrm{P}_{\max }=[14.7(\mathrm{psi} / \mathrm{atm}) \times \mathrm{R}(\mathrm{mole} / \mathrm{s}) \times 22.4(\mathrm{l}-\mathrm{atm} / \mathrm{mole})] / \mathrm{K}(\mathrm{l} / \mathrm{s}) \text { Eq.(5) }
$$

or:

$$
\mathrm{P}_{\max }=164 \mathrm{R}, \mathrm{psig}
$$


The PETN produces 13 moles of gas when totally decomposed. To estimate the time over which this occurs, we refer to Figure 13 to see that it takes over 100 minutes for the $200^{\circ} \mathrm{C}$ temperature to rise from the 1 -inch location to the 5 -inch location. Since the material is spread over roughly this vertical distance, we expect 100 minutes for total decomposition. From Eq.(6) this results in a maximum pressure of $0.4 \mathrm{psig}$. Even if the decomposition is ten times faster, with completion in 10 minutes, the maximum pressure will only be 4.0 psig. This is well within the pressure capacity of the barrel, and therefore the carbon frit provides sufficient flow to prevent rupture of the
barrel.

\subsubsection{Final Series 6(c) test of PETN/clay mixture}

As shown in the photographs below, three barrels packed in the specified manner were supported on a rack with propane burners below. The test was conducted by heating the barrels with the burners to a sufficiently-high temperature that the explosive was certain to decompose (for PETN, a temperature of $200^{\circ} \mathrm{C}$ is sufficient ${ }^{6}$ ). We placed thermocouples in each barrel to ensure that the samples reached a sufficient temperature to fully decompose.

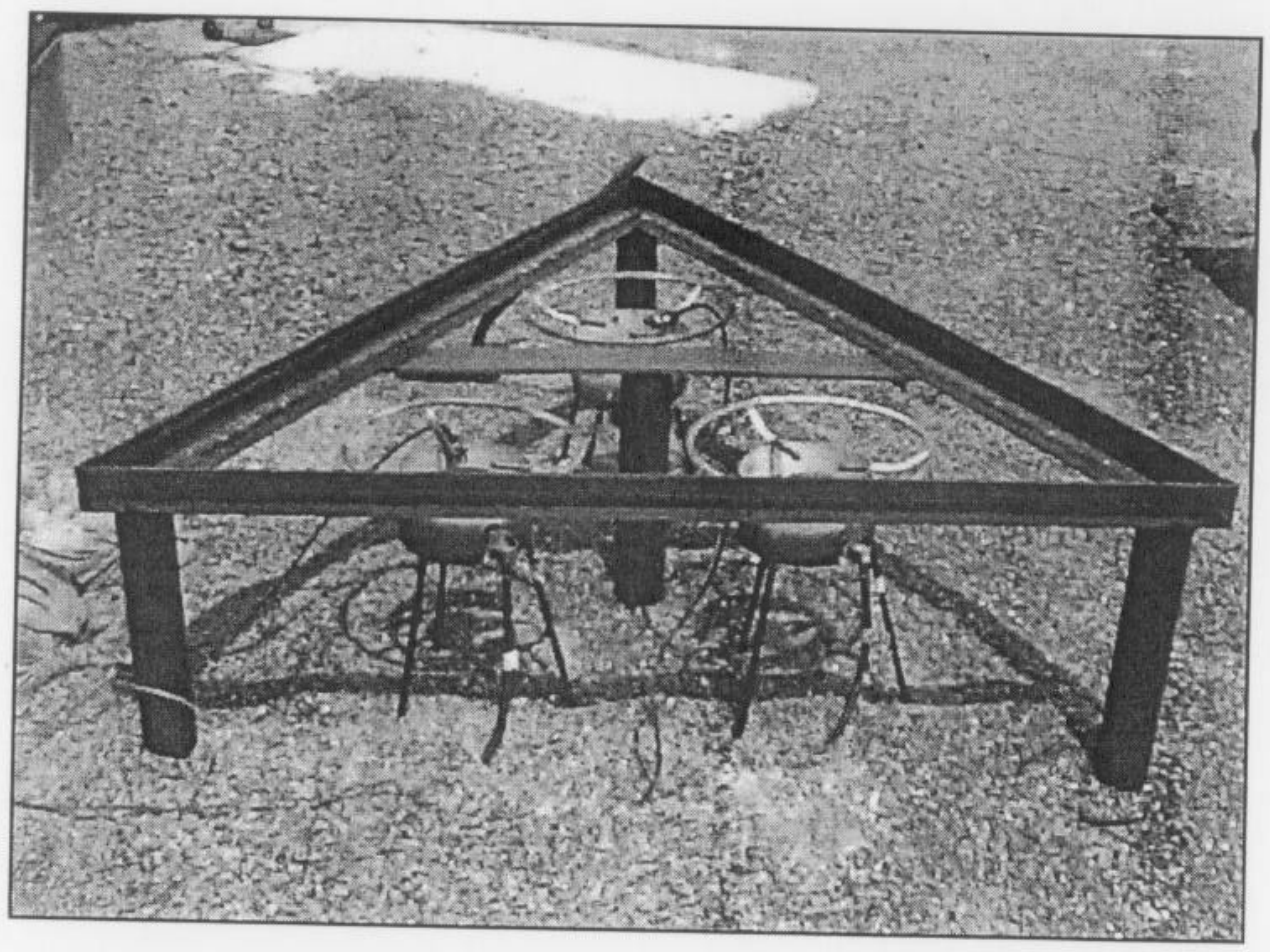

Figure 15. Stand with propane burners beneath. Barrels were mounted on the stand, with one propane burner for each barrel. 


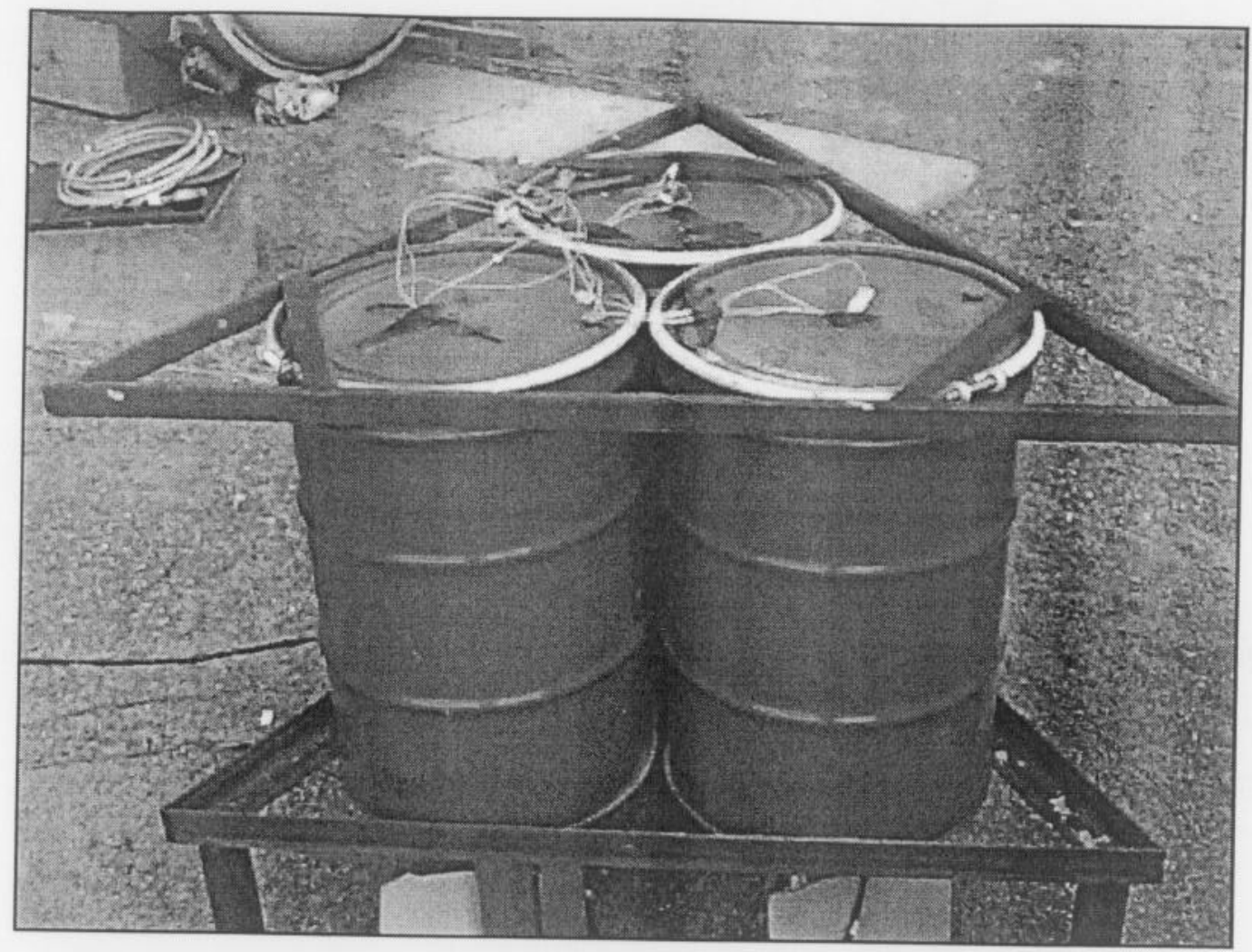

Figure 16. Three barrels on stand for 6(c) fire test. Thermocouple wires can be seen coming out of each lid

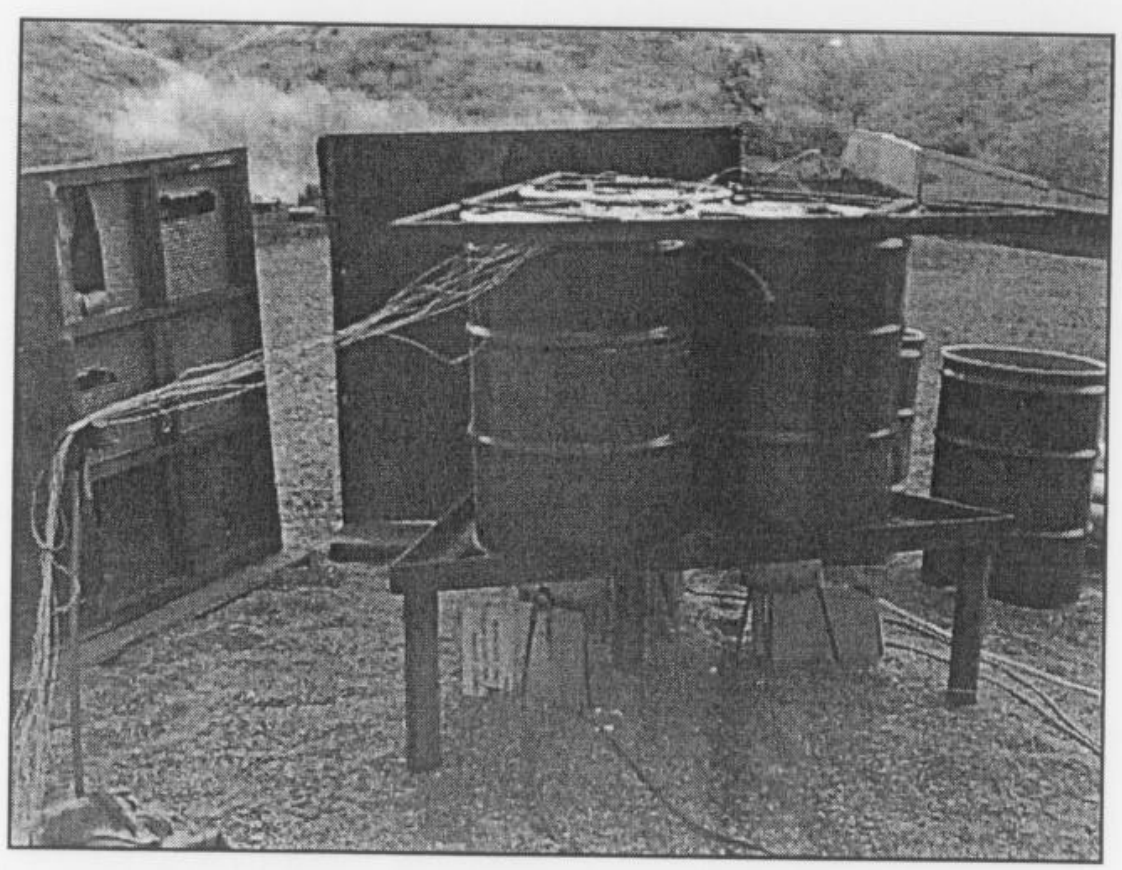

Figure 17. Side view of barrels on stand 


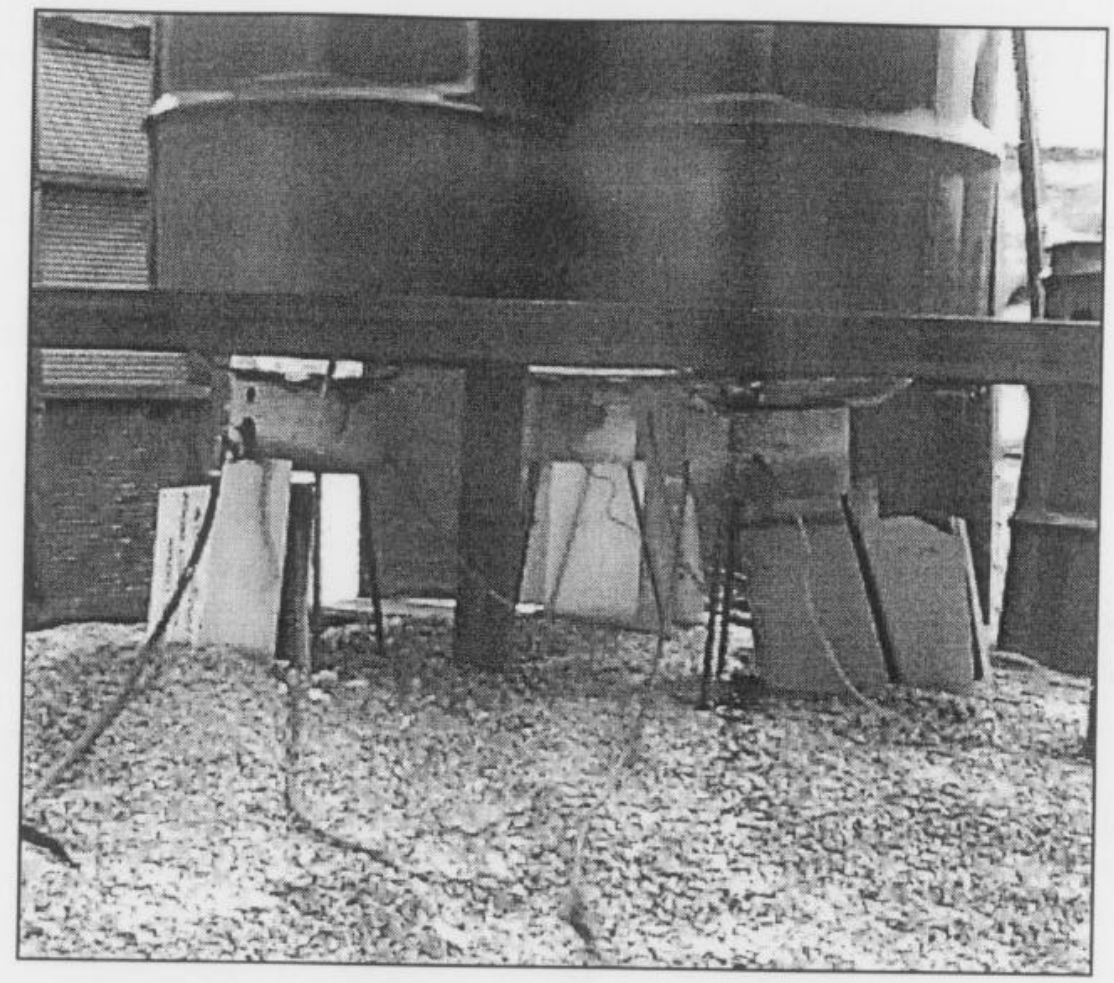

Figure 18. Close-up view of propane burners under each barrel

The barrels were heated for over four hours during the final Series 6(c) test. The internal temperatures, shown in Figures 19-22, indicate that the surrogate waste exceeded $200^{\circ} \mathrm{C}$ in temperature, sufficient to fully decompose the PETN. After the heating was completed and the barrels cooled, they appeared unchanged except for scorched paint on the outside. The plastic bag inside the barrel that had held the surrogate waste was partially melted, but remained partially intact. In short, there was no sign of any reaction. Presumably the PETN was sufficiently dilute that the heat from its exothermic reaction was absorbed by the large mass of inert clay. Since there were no hazardous effects from the packaged material in the fire, the surrogate waste passes the Series 6(c) test as a nonreactive material. 


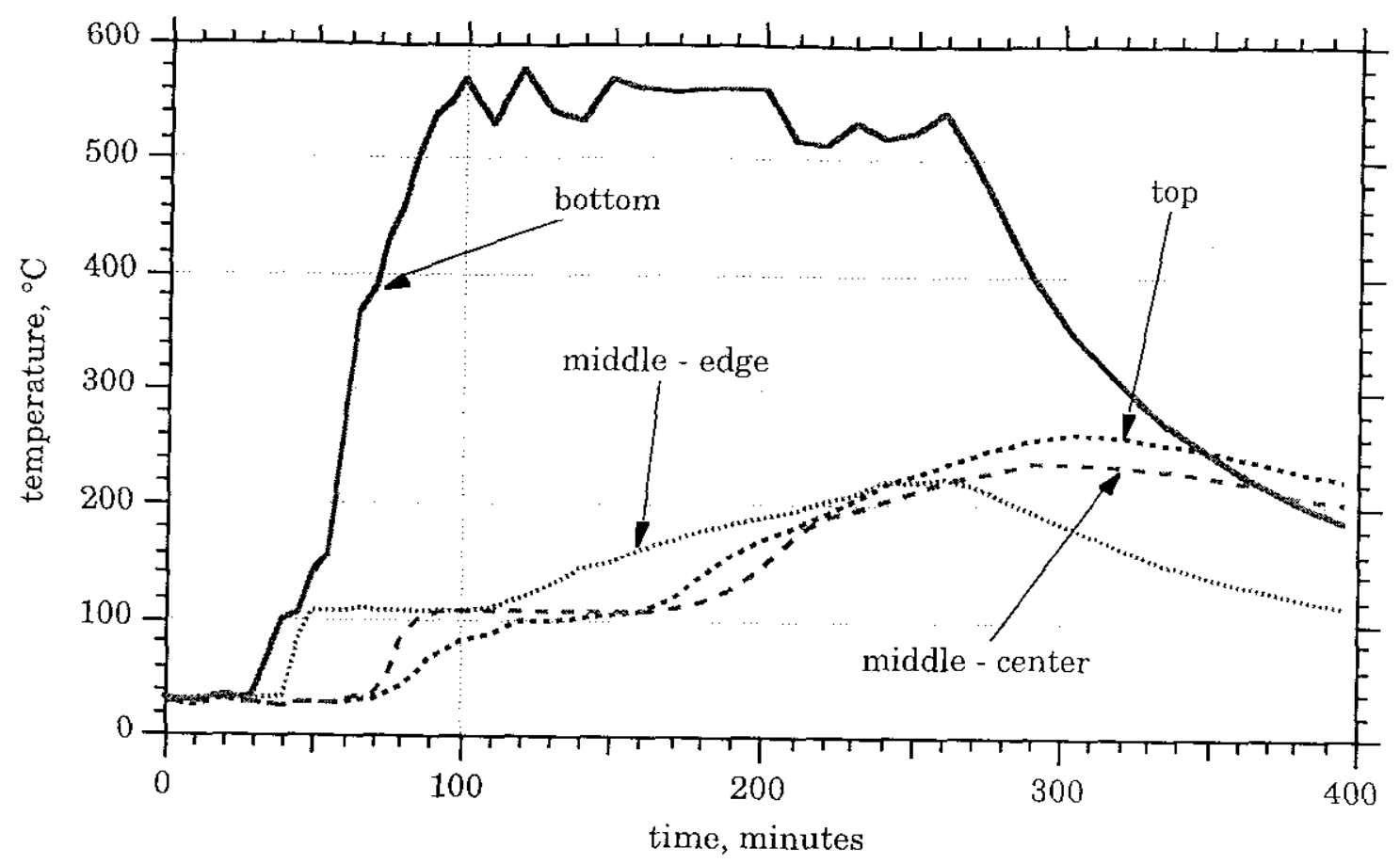

Figure 19. Temperature history of contents in first container during 6(c) test. Note that all thermocouples exceeded $200^{\circ} \mathrm{C}$ during the test, ensuring the decomposition of PETN. Thermocouple locations are labeled with their position with respect to plastic bag of simulated waste.

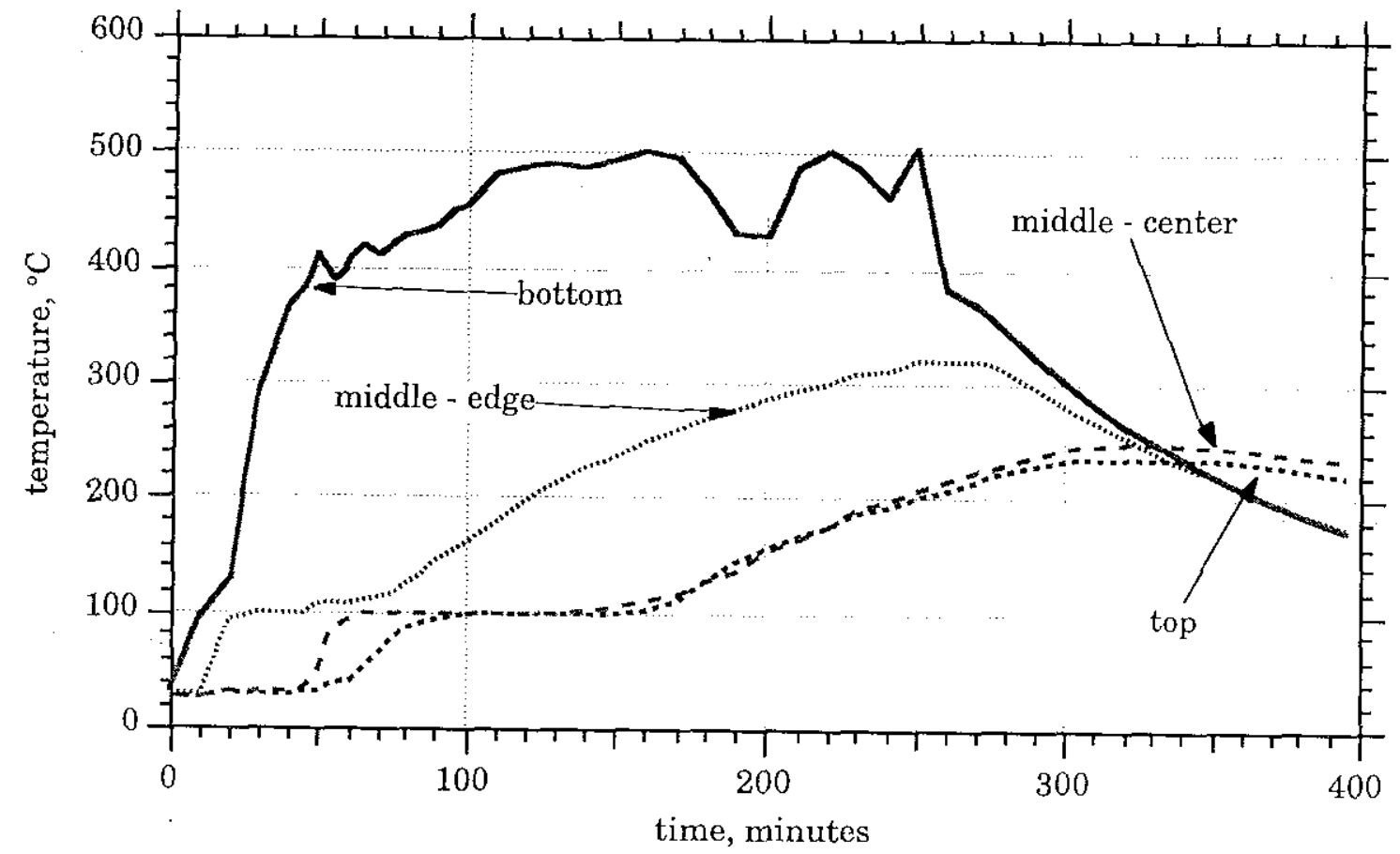

Figure 20. Temperature history of contents in second container during 6(c) test. 


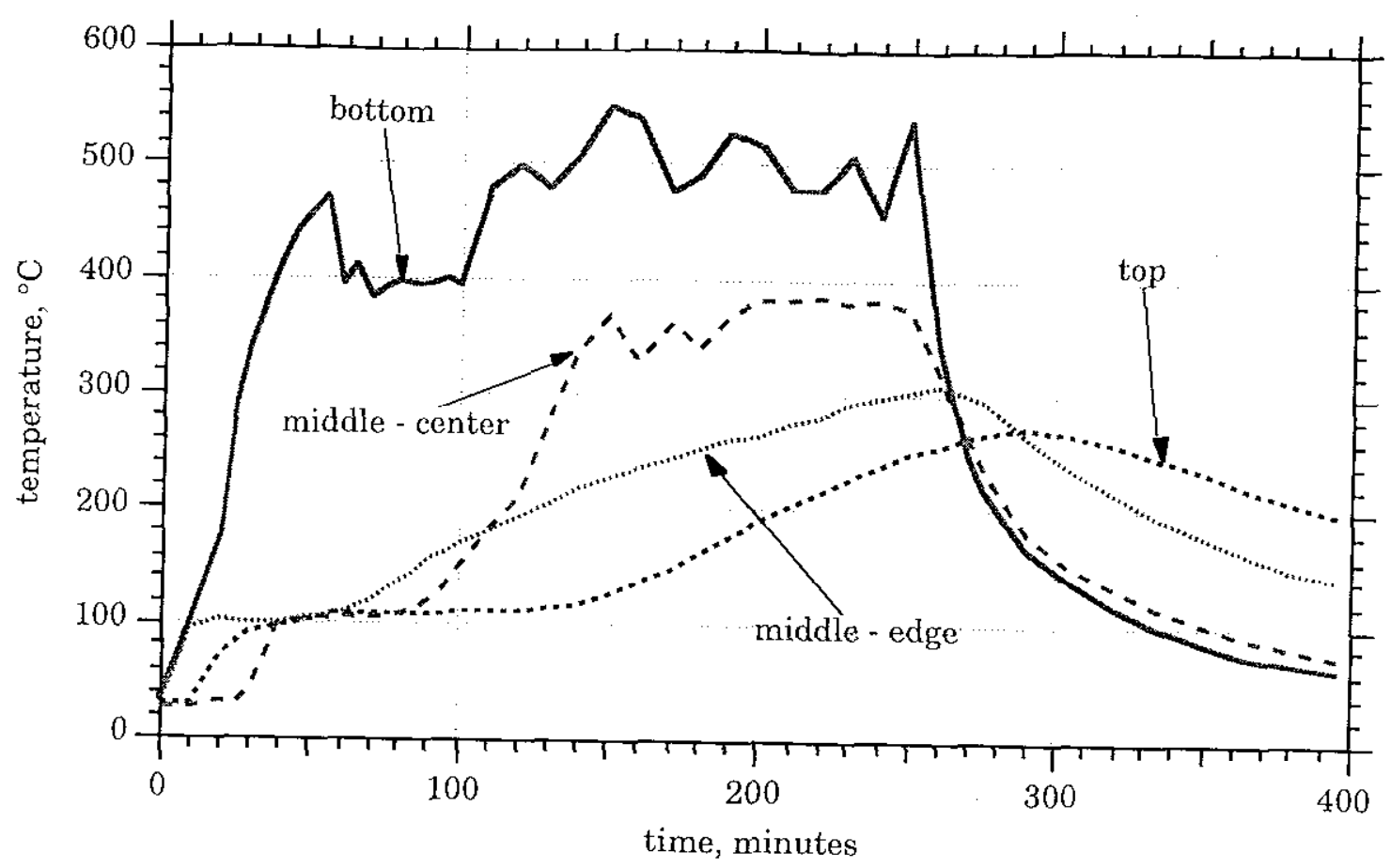

Figure 21. Temperature history of contents in third container during 6(c) test.

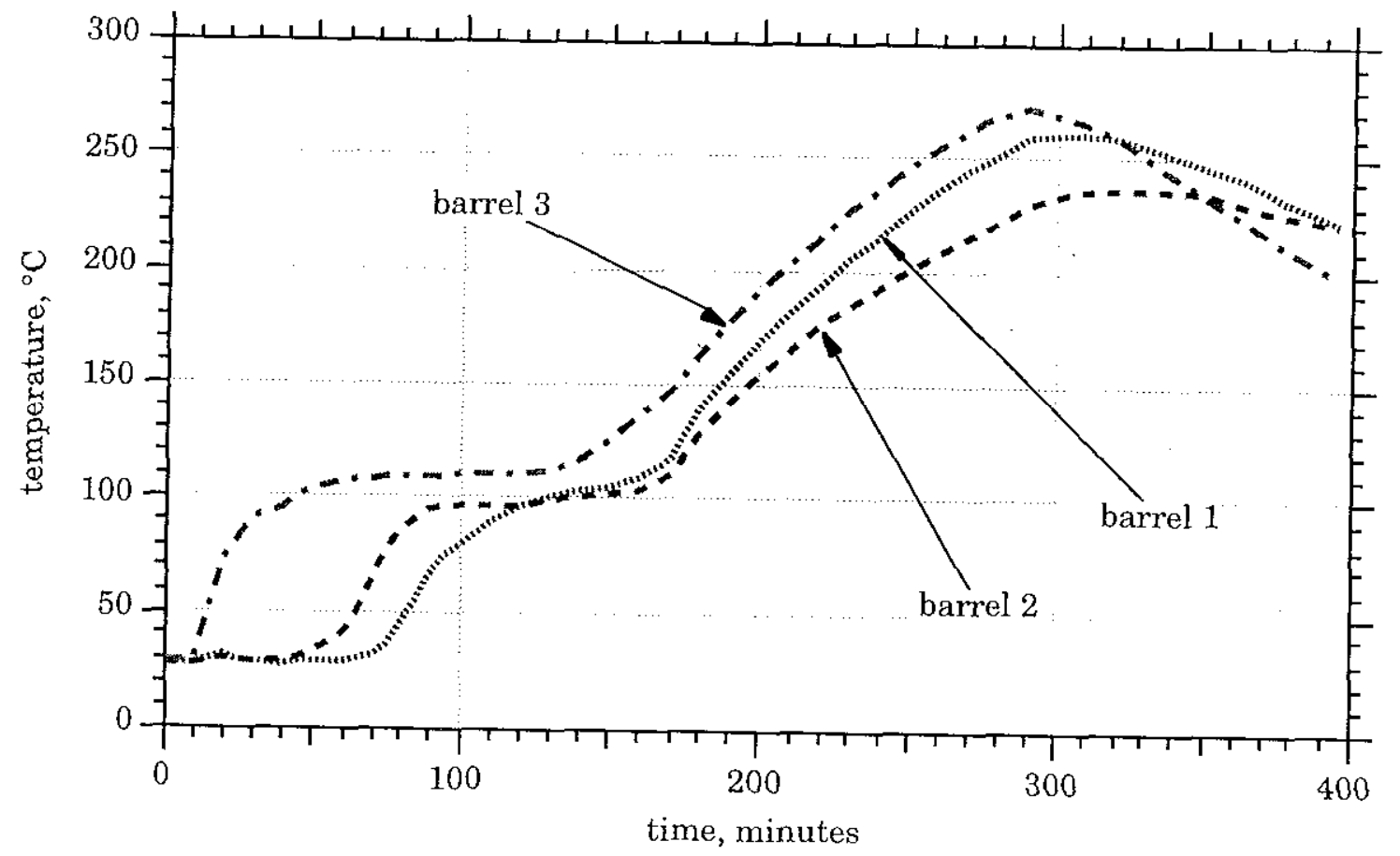

Figure 22. Temperature history at top of surrogate waste (farthest from fire) in all three containers during 6 (c) test. A temperature plateau at $100^{\circ} \mathrm{C}$, resulting from the evaporation of adsorbed water, is quite evident on this plot. 


\subsection{Measurement of explosive concentration by Differential Scanning Calorimetry}

One method to establish the concentration of explosive in debris is through Differential Scanning Calorimetry (DSC) analysis. In DSC, a small sample of waste is heated while the energy released from energetic reactions is measured. The amount of energy released is an indication of the quantity of explosive present in the sample. The DSC technique is implemented with commercial equipment which use small samples (several milligrams).

There are several limitations with DSC. Each explosive responds quantitatively differently in the DSC. Some explosives such as RDX undergo relatively low energy decomposition to volatile products which still contain a large amount of energy. Depending on conditions, much of this energy can be released where it is not measured by the DSC. In contrast, explosives such as TATB decompose mostly to low energy products, so most of the heat of decomposition is seen by the DSC. The net result is that the DSC sensitivity to different explosives is very different. Therefore, two conditions must be met to use DSC to quantify explosive concentration. First, the identity of the explosive must be known. Second, a calibration curve for the DSC of energy release as a function of concentration of that explosive must be measured for known mixtures of the explosive and clay. We also note that care must be taken when sampling debris and clay floor sweep mixture to obtain a representative sample.

We measured the DSC response from several explosives to develop calibration curves and to assess its suitability for these materials. The data are shown in Table 4. We see that the sensitivity varies up to a factor of 5 for different explosives at different concentrations. This indicates that care in calibration is required in order to use DSC to quantify explosive residue in waste. In addition, at low concentrations the thermal peaks in the DSC are not always well-defined, adding further complication to the quantification process. 
Table 4. Differential scanning calorimetry results for mixtures of different explosives and clay. Different explosives show different sensitivities in the DSC (final two columns of data), illustrating the need for calibration of the DSC with a particular explosive to allow its use for quantification of explosive levels in waste residues.

\begin{tabular}{|c|c|c|c|c|c|c|c|c|}
\hline $\begin{array}{c}\text { Run } \\
\text { ID }\end{array}$ & HE & $\begin{array}{c}\text { HE } \\
\text { mass, } \\
\text { mg }\end{array}$ & $\begin{array}{c}\text { sample } \\
\text { mass, } \\
\text { mg }\end{array}$ & $\mid \begin{array}{c}\% \text { HE } \\
\text { in } \\
\text { sample }\end{array}$ & $\begin{array}{c}\text { measured } \\
\text { peak area, } \\
\mathrm{J} / \mathrm{g}\end{array}$ & $\begin{array}{c}\text { total peak } \\
\text { energy, } \\
\mathbf{J}\end{array}$ & $\begin{array}{c}\text { sensitivity } \\
\text { ( } \Delta \mathbf{H} / \mathbf{m a s s}) \\
\mathrm{J} / \mathrm{g}\end{array}$ & $\begin{array}{c}\text { sensitivity } \\
\text { (mass/ } \Delta \mathbf{H}), \\
\mathbf{m g} / \mathbf{J}\end{array}$ \\
\hline $95-041$ & RDX & 0.398 & 7.978 & 5.0 & 31.08 & 0.248 & 623 & 1.605 \\
\hline $95-040$ & RDX & 0.399 & 7.969 & 5.0 & 20.21 & 0.161 & 404 & 2.477 \\
\hline $95-039$ & RDX & 0.427 & 8.049 & 5.3 & 18.89 & 0.152 & 356 & 2.808 \\
\hline $92-085$ & RDX & 0.527 & 5.266 & 10.0 & 155.50 & 0.819 & 1554 & 0.644 \\
\hline $92-086$ & $\mathrm{RDX}$ & 0.700 & 3.500 & 20.0 & 209.60 & 0.734 & 1048 & 0.954 \\
\hline $94-240$ & $\mathrm{RDX}$ & 0.754 & 5.025 & 15.0 & 122.70 & 0.617 & 818 & 1.223 \\
\hline $95-044$ & RDX & 0.796 & 8.006 & 9.9 & 91.20 & 0.730 & 917 & 1.090 \\
\hline 95-042 & RDX & 0.830 & 8.023 & 10.3 & 106.00 & 0.850 & 1025 & 0.976 \\
\hline $95-043$ & $\mathrm{RDX}$ & 0.839 & 8.022 & 10.5 & 131.00 & 1.051 & 1253 & 0.798 \\
\hline $94-239$ & $\mathrm{RDX}$ & 0.910 & 6.068 & 15.0 & 140.00 & 0.850 & 934 & 1.071 \\
\hline 95-047 & RDX & 1.184 & 7.995 & 14.8 & 162.60 & 1.300 & 1098 & 0.911 \\
\hline $95-045$ & RDX & 1.186 & 7.999 & 14.8 & 117.40 & 0.939 & 792 & 1.263 \\
\hline $95-046$ & $\mathrm{RDX}$ & 1.197 & 8.005 & 15.0 & 148.10 & 1.186 & 990 & 1.010 \\
\hline $95-050$ & $\mathrm{HMX}$ & 0.452 & 4.050 & 11.2 & 162.70 & 0.659 & 1458 & 0.686 \\
\hline $95-051$ & HMX & 0.396 & 4.001 & 9.9 & 116.90 & 0.468 & 1181 & 0.847 \\
\hline 95-049 & TATB & 0.793 & 8.001 & 9.9 & 217.30 & 1.739 & 2192 & 0.456 \\
\hline $95-048$ & TATB & 0.814 & 8.009 & 10.2 & 193.40 & 1.549 & 1903 & 0.526 \\
\hline $95-052$ & $\mathrm{TNT}$ & 0.798 & 7.993 & 10.0 & 211.20 & 1.688 & 2115 & 0.473 \\
\hline $95-053$ & TNT & 0.862 & 8.060 & 10.7 & 173.90 & 1.402 & 1626 & 0.615 \\
\hline $95-054$ & PETN & 0.398 & 4.005 & 9.9 & 151.70 & 0.608 & 1527 & 0.655 \\
\hline $95-055$ & PETN & 0.398 & 4.005 & 9.9 & 148.00 & 0.593 & 1489 & 0.671 \\
\hline
\end{tabular}




\subsection{References}

1. Recommendations on the Transport of Dangerous Goods. Manual of Tests and Criteria, Second Revised Edition, ST/SG/AC.10/11/Rev.2, United Nations, New York (1995).

2. L. Green, R. Garza, J. Maienschein and C. Pruneda, "Program for Certification of Waste from Contained Firing Facility - Establishment of Waste as Non-Reactive and Discussion of Potential Waste Generation Problems", Lawrence Livermore National Laboratory, UCRL-ID-128999 (November, 1997).

3. L.R. Simpson and M.F. Foltz, "LLNL Small-Scale Drop-Hammer Impact Sensitivity Test", Lawrence Livermore National Laboratory, UCRL-ID119665 (January 1995).

4. L.R. Simpson and M.F. Foltz, "LLNL Small-Scale Friction Sensitivity (BAM) Test", Lawrence Livermore National Laboratory, UCRL-ID-124563 (June 1996).

5. D.W. Prokosch and F.Garcia, "Chemical Reactivity Test for Thermal Stability", Lawrence Livermore National Laboratory, UCRL-JC-117941 (July 1994).

6. B.M. Dobratz and P.C. Crawford, "LLNL Explosives Handbook:

Properties of Chemical Explosives and Explosive Simulants", Lawrence Livermore National Laboratory, UCRL-52997 Change 2 (January 31, 1985).

7. L.E. Fried, "CHEETAH 1.39 User's Manual", Lawrence Livermore National Laboratory, UCRL-MA-117541 Rev. 3 (March 19, 1996). 